\title{
Research Paper \\ Protective Effects of Vitamin C Concomitant Treatment on Deferasirox-induced Renal Toxicity in Rats
}

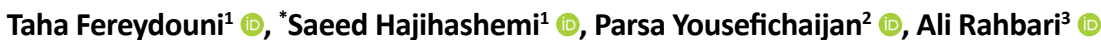

1. Department of Physiology, School of Medicine, Arak University of Medical Sciences, Arak, Iran

2. Department of Children, School of Medicine, Arak University of Medical Sciences, Arak, Iran.

3. Department of Pathology, School of Medicine, Arak University of Medical Sciences, Arak, Iran

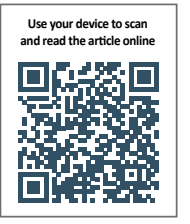

Citation: Fereydouni T, Hajihashemi S, Yousefichaijan P, Rahbari A. [Protective Effects of Co-treatment With Vitamin C on the Renal Toxicity Induced by Deferasirox in Rats (Persian)]. Journal of Arak University of Medical Sciences (JAMS). 2020; 23(6):926-943. https://doi.org/10.32598/JAMS.23.6.62.7

\section{(i) (8)}

Article Info:

Received: 18 Jul 2020

Accepted: 27 Sep 2020

Available Online: 01 Dec 2020

Keywords:

Renal toxicity, Vitamin C, Deferasirox, Exjade, Rat

\section{ABSTRACT}

Background and Aim Deferasirox (Exjade) is an iron-chelating drug used in patients with beta-thalassemia major. Oxidative stress is among $f$ the major causes of nephrotoxicity and its progression. Deferasirox, due to oxidative stress and increased cell apoptosis causes the dysfunction of renal tubules and renal toxicity. According to its antioxidant and anti-inflammatory properties, the present study explored the effect of vitamin $\mathrm{C}$ on deferasirox-induced kidney damage.

Methods \& Materials This study was performed on 30 Wistar rats in 3 groups of control, deferasirox, and deferasirox plus vitamin C. To induce the nephrotoxicity, the intra-peritoneum injection of deferasirox (75 $\mathrm{mg} / \mathrm{kg} /$ day) was used. After taking plasma from the blood samples of the explored rats, we determined the values of $\mathrm{Cr}, \mathrm{Na}+, \mathrm{K}+, \mathrm{Mg}+$, osmolality, and BUN in the obtained plasma and urine samples. The creatinine clearance, as well as the relative and absolute excretion of sodium and potassium, were also calculated. After separating the two kidneys, they were used for the histologic study with Hematoxylin and Eosin (H\&E) staining, as well as Malondialdehyde (MDA) and Ferric Reducing Antioxidant Power (FRAP) biochemical studies.

Ethical Considerations This study was approved by the Research Ethics Committee of Arak University of Medical Sciences (Code: IR.ARAKMU.REC.1396.309).

Results Cotreatment with deferasirox and vitamin C reduced renal tissue MDA and relative and absolute $\mathrm{Na}$ and $\mathrm{K}$ excretion and urine osmolarity; this method also increased creatinine clearance and renal tissue FRAP. Conclusion The co-administration of vitamin C presented a significant protective effect on the renal toxicity induced by deferasirox. The protective property of deferasirox is because of the antioxidant impacts of vitamin $\mathrm{C}$ in reducing oxidative stress and lipid peroxidation.

\section{Extended Abstract}

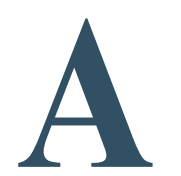

\section{Introduction}

cute renal failure is a sudden decrease in renal function due to renal toxicity $[2,3]$. Deferasirox or oxide can generate acute renal failure due to the oxidative stress and dysfunction of the renal tubules by increasing cell apoptosis.

Deferasirox is a selective iron chelator. It is used to treat chronic iron overload conditions caused by repeated blood transfusions in patients with beta-thalassemia major $[5,6]$.

\section{* Corresponding Author:}

Saeed Hajihashemi, PhD.

Address: Department of Physiology, School of Medicine, Arak University of Medical Sciences, Arak, Iran.

Tel: 98 (861) 34173502

E-mail: hajihashemi@arakmu.ac.ir 
Vitamin C, as an essential coenzyme and antioxidant, prevents cell membrane damage caused by oxidative radicals [7]. Therefore, using antioxidants, like vitamin $\mathrm{C}$ can be effective for the treatment or prevention of deferasiroxinduced kidney damage. This study investigated the effect of the concomitant use of vitamin $\mathrm{C}$ on the renal toxicity of deferasirox.

\section{Materials and Methods}

This experimental study was performed on 30 rats of Wistar breed in 3 groups of control, deferasirox, and deferasirox plus vitamin C. Deferasirox (75 $\mathrm{mg} / \mathrm{kg} /$ day) was intraperitoneally injected for 8 days to induce renal toxicity. In the concomitant treatment group, in addition to deferasirox (75 mg/kg/day), vitamin C $200 \mathrm{mg} / \mathrm{kg}$ /day was intraperitoneally injected for 8 days. On the eighth day, the explored animals were placed in a metabolic cage for 6 hours; after collecting urine samples, they were anesthetized. Then, the required blood sample was obtained from the aorta using a heparin syringe.

After plasma extraction from the rat blood samples, the concentrations of $\mathrm{Cr},+\mathrm{Na},+\mathrm{K},+\mathrm{Mg}$, osmolality, and BUN in plasma and urine samples were determined. Accordingly, renal creatinine clearance $(\mathrm{Cr})$, as well as the absolute and relative excretion of sodium and potassium were calculated. Kidney tissue was stained by Hematoxylin and Eosin (H\&E) staining for histological study; antioxidant capacity was measured by FRAP and lipid peroxidation by MDA for biochemical study $[12,13]$.

The percentage of damage caused by the pathologist was determined and graded as follows: The lack of damage equivalent to zero degrees; damage between $1 \%$ to $25 \%$ equivalent to grade 1 ; damage between $25 \%$ to $50 \%$ equivalent to grade 2 ; damage between $50 \%$ to $75 \%$ equivalent to grade 3 , and damage between $75 \%$ to $100 \%$ equivalent to grade 4 [15].

\section{Results}

The present research results revealed that creatinine clearance in the group treated with vitamin $\mathrm{C}(1.63 \pm 0.1 \mathrm{~mL} / \mathrm{min} /$ $\mathrm{kg}$ ) was significantly different, compared to that in the deferasirox group $(0.59 \pm 0.1 \mathrm{~mL} / \mathrm{min} / \mathrm{kg}, \mathrm{P}<0.001)$ (Figure 1).

The relative excretion of sodium and potassium was significantly different, compared with the deferasirox group $(\mathrm{P}<0.001)$. The absolute excretion of sodium was significantly different in the concomitant treatment group with vitamin C ( $2.46 \pm 0.087 \mathrm{mmol} / \mathrm{min} / \mathrm{kg})$, compared with the deferasirox group $(001.15 \pm 0.04 \mathrm{mmol} / \mathrm{min} / \mathrm{kg}, \mathrm{P}<0.7)$. The absolute excretion of potassium was significantly higher in the deferasirox group $(13.41 \pm 0.098 \mathrm{mmol} / \mathrm{min} / \mathrm{kg}$, $)$ compared with the vitamin C group $(2.986 \pm 0.163 \mathrm{mmol} / \mathrm{mi} /$ $\mathrm{kg})(\mathrm{P}<0.001)$.

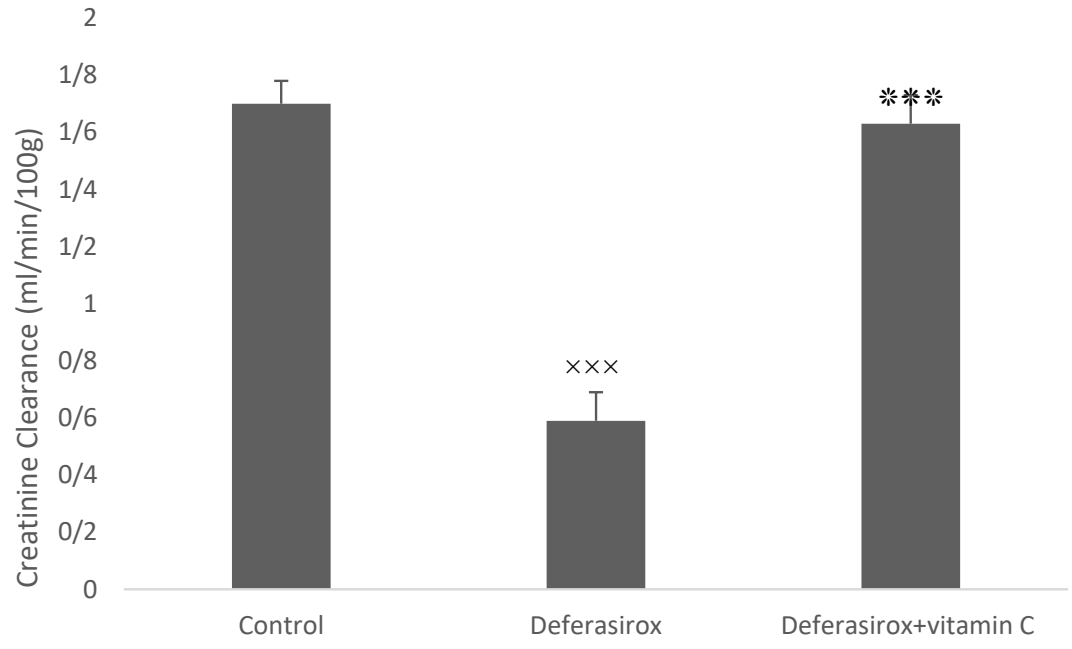

Figure 1. Comparing creatinine clearance between the research groups

${ }^{\times \times \times} \mathrm{P}<0.001$ compared to the control group; ${ }^{* * *} \mathrm{P}<0.001$ compared to the deferasirox group, one-way Analysis of Variance (ANOVA) and Tukey's test (Mean \pm SEM). N=10, compared with the control group, creatinine clearance was significantly lower in the deferasirox group $(\mathrm{P}<0.001)$. There was a significant difference between the concomitant treatment group with vitamin $\mathrm{C}$ and the deferasirox group $(\mathrm{P}<0.001)$. 


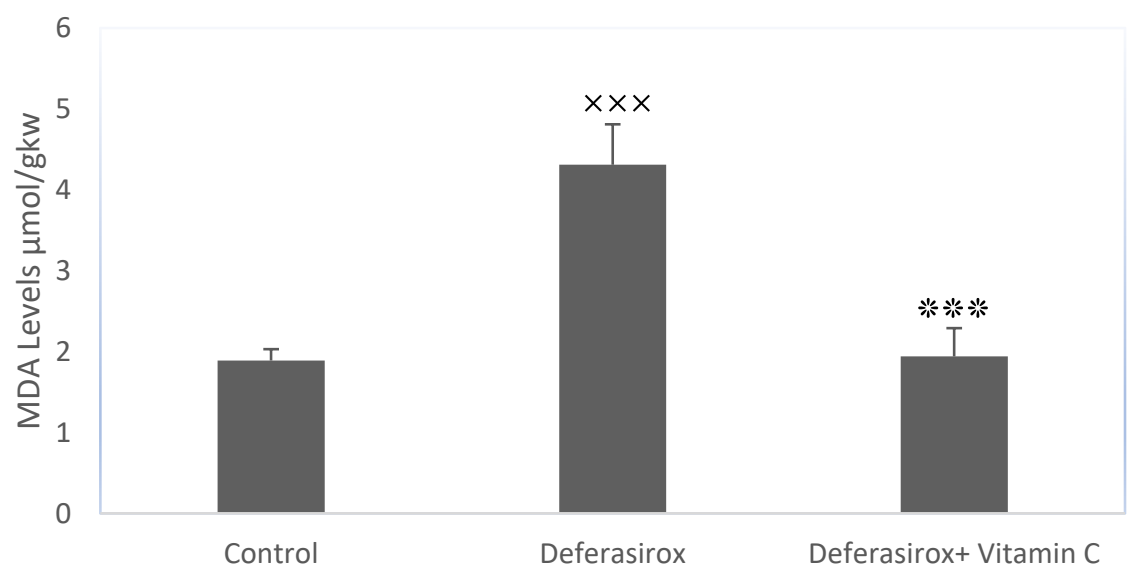

Figure 2. Comparing renal tissue MDA levels between the study groups

Sournal of

${ }^{\times \times \times} \mathrm{P}<0.001$ compared with the control group; ${ }^{* * *} \mathrm{P}<0.001$ compared with the deferasirox group. One-way ANOVA and Tukey's test $(\mathrm{Mean} \pm \mathrm{SEM})(\mathrm{n}=10)$ were significantly higher in the deferasirox group, compared to the control group $(\mathrm{P}<0.001)$. There was a significant difference between the vitamin $\mathrm{C}$ treatment groups, compared to the deferasirox group $(\mathrm{P}<0.001)$.

The obtained data revealed that urinary creatinine concentration in the deferasirox group $(32.7 \pm 1.55 \mathrm{mg} / \mathrm{dL})$ was significantly lower than that of the concomitant treatment group with vitamin $\mathrm{C}(69.8 \pm 6.7 \mathrm{mg} / \mathrm{dL})(\mathrm{P}<0.001)$. Urinary urea concentration in the concomitant treatment group with vitamin $\mathrm{C}(137 \pm 3.82 \mathrm{mg} / \mathrm{dL})$ was significantly increased, compared to the deferasirox group $(72 \pm 0.14 \mathrm{mg}$ / dL) $(\mathrm{P}<0.001)$. Urinary sodium concentration signified that the concomitant treatment group with vitamin C (127.4 \pm 3.1 $\mu \mathrm{mol} / \mathrm{mL}$ ) had lower values than the deferasirox group $(220.4 \pm 4.55 \mu \mathrm{mol} / \mathrm{mL})(\mathrm{P}<0.001)$. Urine osmolality in the

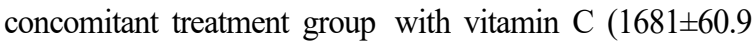
$\mathrm{mOsm} / \mathrm{kgH} 2 \mathrm{O}$ ) was significantly reduced, compared to the deferasirox group $(612.5 \pm 18 \mathrm{mOsm} / \mathrm{kgH} 2 \mathrm{O})(\mathrm{P}<0.001)$.

The level of tissue MDA in the concomitant treatment group with vitamin C $(1.94 \pm 0.355 \mu \mathrm{mol} / \mathrm{gkw})$ was significantly reduced, compared to the deferasirox group ( $4.31 \pm 0.5$ $\mu \mathrm{mol} / \mathrm{gkw}, \mathrm{P}<0.001$ ) (Figure 2).

Renal tissue FRAP level was significantly increased in the concomitant treatment with vitamin $\mathrm{C}(1.07 \pm 0.25 \mu \mathrm{mol} /$ $\mathrm{gkw}$, compared with the deferasirox group $(001.75 \pm 0.61$ $\mu \mathrm{mol} / \mathrm{gkw}, \mathrm{P}<0.0$ ) (Figure 3).

In the concomitant treatment group with vitamin $\mathrm{C}$, the amount of tubular cell necrosis, the formation of protein molds in the lumen of the tubule, the vacuolation of tubular cells, and the increase in the space of the Bowman capsule were significantly differe $\mathrm{n} t$, compared to the deferasirox group $(\mathrm{P}<0.001)$.

\section{Discussion}

The current study results indicated that vitamin C decreased renal toxicity due to deferasirox by reducing plasma urea and creatinine, the relative and absolute excretion of sodium and potassium and MDA, as well as increasing creatinine clearance and FRAP. The concomitant use of vitamin $\mathrm{C}$ plus deferasirox protects kidneys by reducing oxidative stress. Previous studies reported that vitamin $\mathrm{C}$ reduces oxidative stress during gentamicin nephrotoxicity [2].

An effective factor in causing deferasirox-induced kidney damage is oxidative stress, which increased MDA and decreased FRAP.

As in previous studies, mice treated with vitamin $\mathrm{C}$ had lower levels of MDA than the deferasirox group. Furthermore, the extent of FRAP in the tissue of all explored rats treated with vitamin $\mathrm{C}$ was much higher than that in the deferasirox group [9].

In the vitamin $\mathrm{C}$ concomitant treatment group, compared with the deferasirox group, a lower rate of relative excretion of sodium and potassium ions was observed; thus, such data indicated the prevention of kidney damage. The effect of vitamin $\mathrm{C}$ on the renal toxicity of deferasirox with decreasing creatinine and blood urea, and tissue MDA with decreasing 


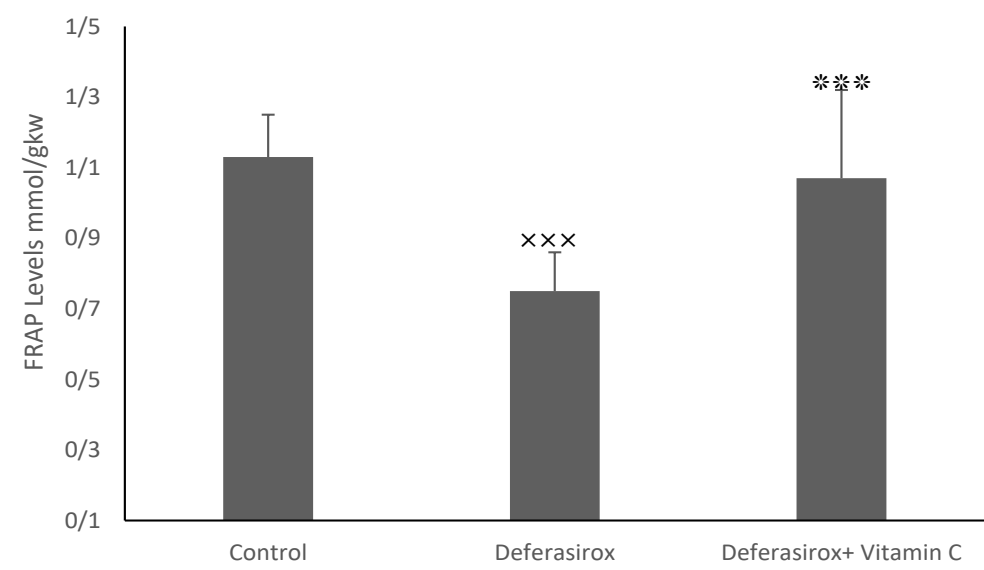

Figure 3. Comparing renal tissue FRAP levels between the research groups

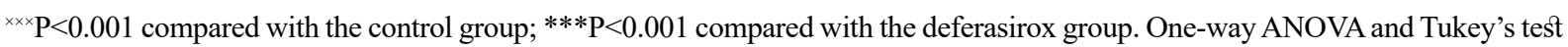
$(\mathrm{Mean} \pm \mathrm{SEM})(\mathrm{n}=10)$. Compared with the controls, the amount of FRAP was significantly lower in the deferasirox group $(\mathrm{P}<0.001)$. There was no significant difference between the vitamin $\mathrm{C}$ treatment groups and the deferasirox group $(\mathrm{P}<0.001)$.

oxidative stress is similar to the effect of vitamin $\mathrm{C}$ on the renal toxicity of gentamicin [9]. Vitamin $\mathrm{C}$ reduces the renal toxicity induced by deferasirox administration by decreasing oxygen species. In this study, in line with the previous studies, administrating vitamin $\mathrm{C}$ significantly maintained creatinine clearance and significantly increased plasma creatinine concentration, compared to the deferasirox group [9, $17,25]$.

Oxidative stress is a major factor in the development of the renal toxicity of deferasirox with the destruction of epithelial cells; increased necrosis and fibrosis of renal tissue; as well as tubular and glomerular atrophy on renal function $[4,22]$. The kidney toxicity of deferasirox is believed to be due to the production of oxygen free radicals; the increased production of cytokines; as well as the induction of apoptosis and necrosis [23]. Apoptosis plays a crucial role in cell death and may be involved in the removal of damaged cells [16].

\section{Conclusion}

The concomitant administration of vitamin $\mathrm{C}$ in treatment with deferasirox presented a significant efficacy in maintaining renal function. The protective effect of vitamin $\mathrm{C}$ is due to its antioxidant properties and the trapping of free radicals. It prevented hemodynamic changes in the kidneys, impaired salt excretion, and tissue changes caused by deferasirox.

\section{Ethical Considerations}

\section{Compliance with ethical guidelines}

This study was approved by the Research Ethics Committee of Arak University of Medical Sciences (code: IR.ARAKMU.REC.1396.309). All ethical codes approved by the Ministry of Health and Medical Education and Arak University of Medical Sciences were observed regarding maintenance and testing in this investigation.

\section{Funding}

This article was extracted from the $\mathrm{PhD}$. dissertation of first author at the Department of Physiology, School of Medicine, Arak University of Medical Sciences, Arak.

\section{Authors' contributions}

Methodology, validation, data analysis, and writing: Dr. Saeed Haji Hashemi; Conducting research experiments, resources, and drafts: Dr. Taha Fereydoni and Dr. Ali Rahbari; Conceptualization: Dr. Parsa Yousefi Chaijan.

\section{Conflicts of interest}

The authors declared no conflicts of interest.

\section{Acknowledgements}

The authors would like to thank the Vice-Chancellor for Research and Technology of Arak University of Medical Sciences for their support. 
This Page Intentionally Left Blank 


\section{مقاله يُوهشى:}

اثرات حفاظثى درمان همزمان با ويتامين C روى سميت كليوى ناشى از مصرف دفراسيروكس در زت

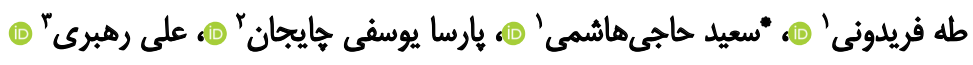

ا. كروه فيزيولوزي، دانشكده يزشكى، دانشكاه علوميزشكى اراك، اراك، ايران.

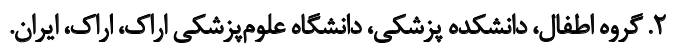

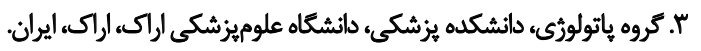

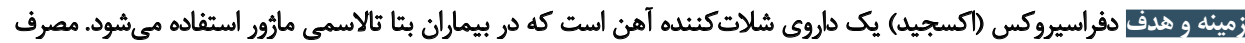

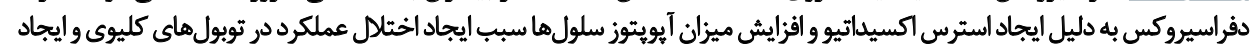

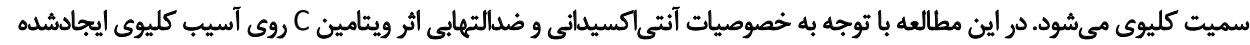
توسط دفراسيروكس بررسى شلد.

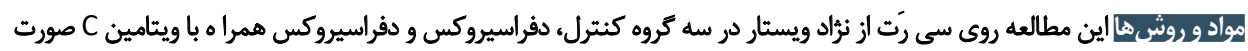

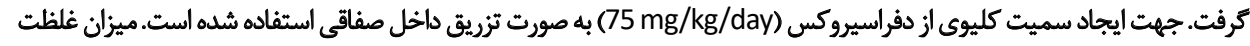

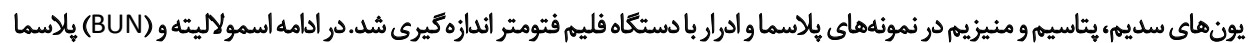

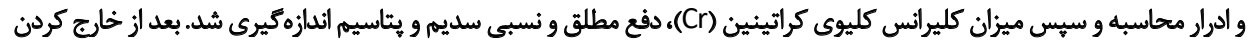

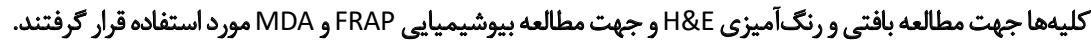

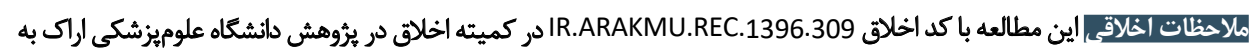
ثبت رسيله استث.

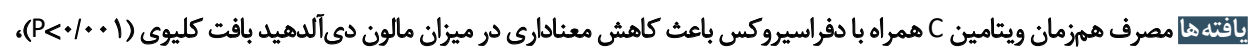

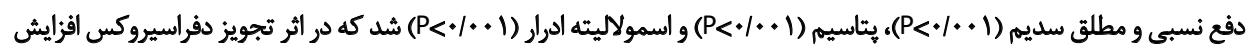

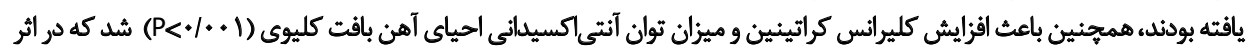
تجويز دفراسيروكس كاهش يافته بودئد.

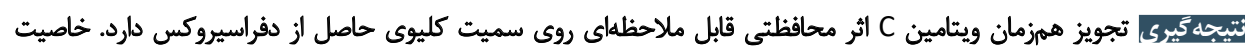

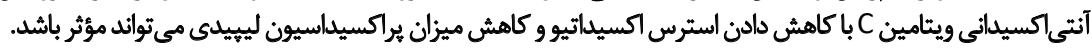

اطلاعات مقاله:

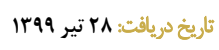

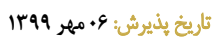

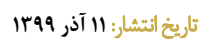

: Lojlgen

سميت كليوى، ويتامين C، دفراسيروكس، اكسجيلد، رت وت

در اين نوع سميت كليوى اسمولاليته ادرار افزايش و حجم آن آن

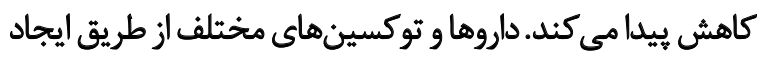

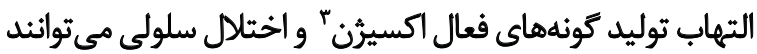

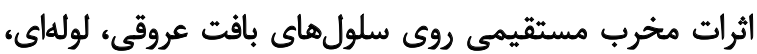

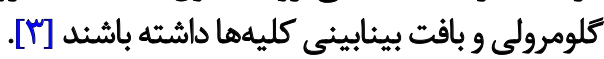

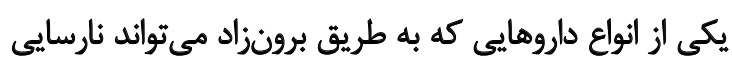

نارسايى حاد كليه يك كاهش ناكهانى در عملكرد كليه ناشي از

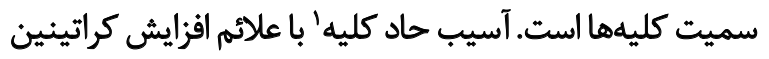

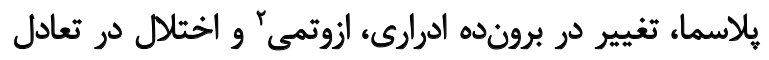

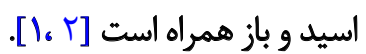




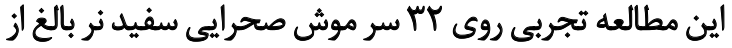

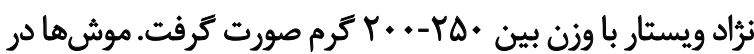

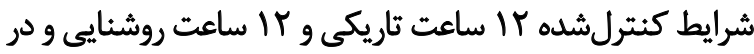

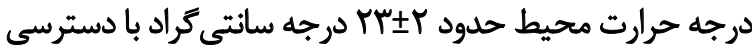

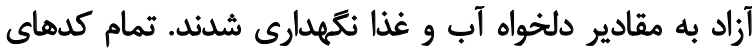

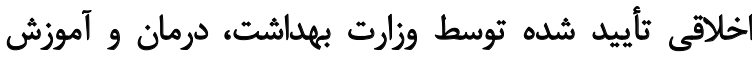

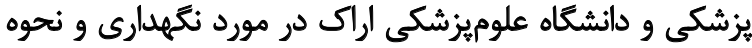

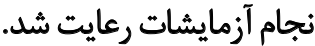

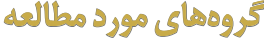

كروه كنترل: موشهاى اين كروه هيجّونه دارو دريافت نكردند

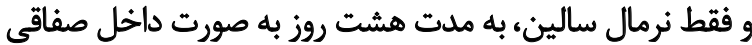
تزريق شد (•ln=1).

كروه با سميت كليوى دفراسيروكس: به موشهاي اين كروه

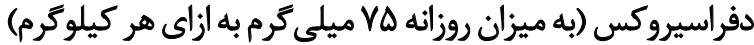

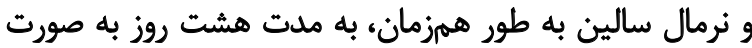

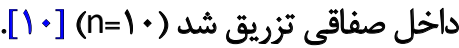

ب- كروه دفراسيروكس ودرمان همزمان باويتامين C: موشهاى

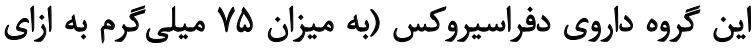

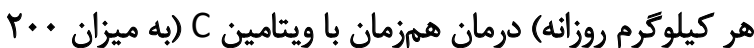

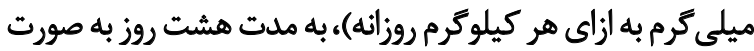

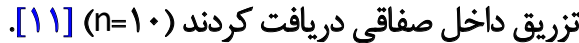

در روز هشتم حيوانات به مدت شش ساعت در قفس متابوليك

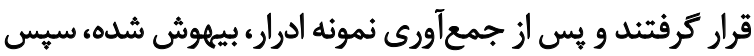

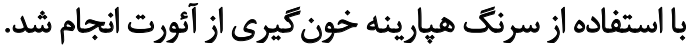

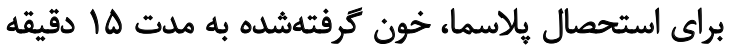

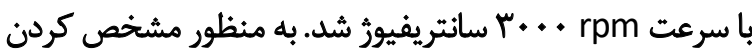

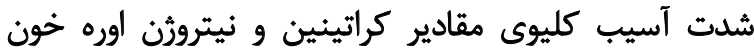

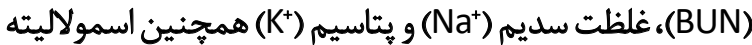

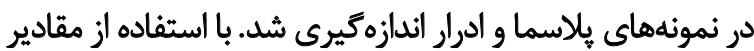

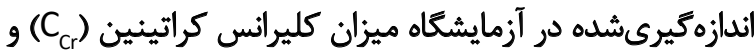

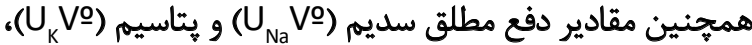

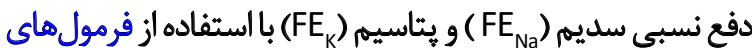

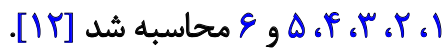

.1

$\mathrm{V}^{\circ}(\mu \mathrm{l} / \mathrm{min} \cdot \mathrm{gkw})=(1000 \times \mathrm{UFR}) /(\mathrm{KW} \times 720)$

$\mathrm{C}_{\mathrm{Cr}}(\mathrm{ml} / \mathrm{min} \cdot \mathrm{gkw})=\left(\mathrm{V}^{\circ} / 1000 \times \mathrm{U}_{\mathrm{Cr}}\right) / \mathrm{P}_{\mathrm{Cr}}$

r

$U_{\mathrm{Na}} \mathrm{V}^{\circ}(\mu \mathrm{mol} / \mathrm{min} \cdot \mathrm{gkw})=\left(\mathrm{V}^{\circ} \times \mathrm{U}^{\mathrm{Na}}\right) / 1000$
حاد كليوى ايجاد كند، دفراسيروكس" (اكسجيد)ه است.

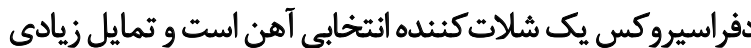

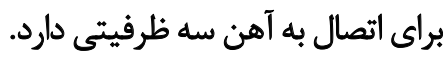

از اين دارو براى درمان وضعيتهاى بيش بار مزمن آهن

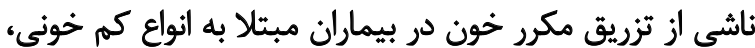

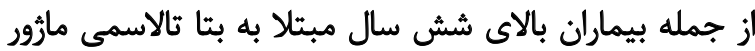

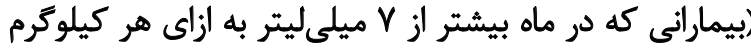

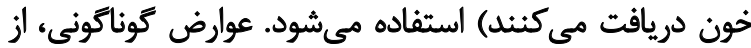

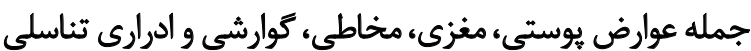

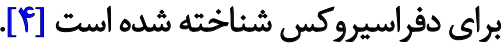

مصرف دفراسيروكس به دليل ايجاد استرس اكسيداتيو و إوبروي

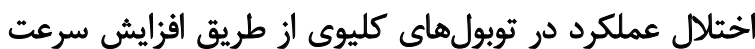

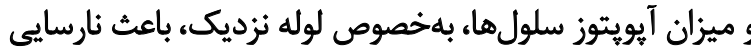

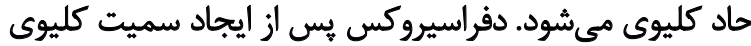

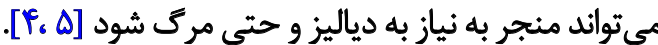
ويتامين C6H8O6) C با نام علمى آسكوربيك اسيد يك

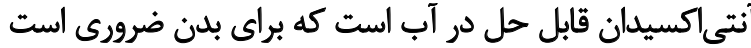

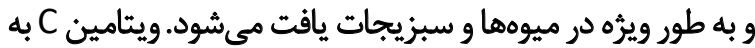

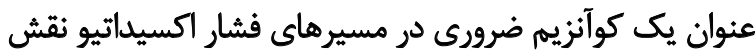

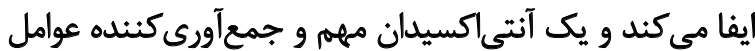

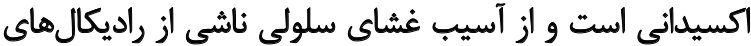

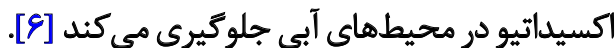

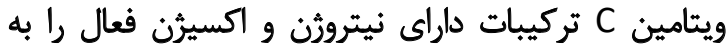

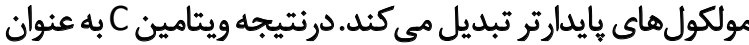

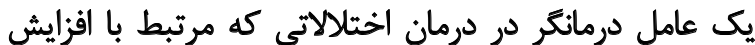

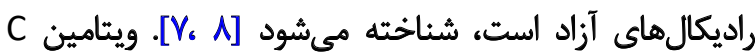

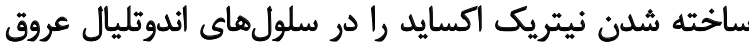

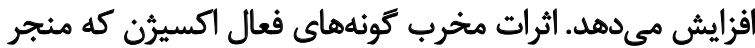

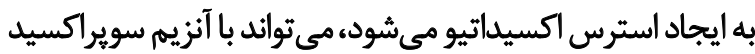

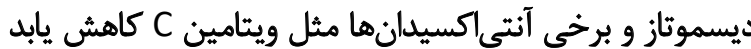
$[\%, 9]$

مطالعات قبلى نشان داده است كه استرس اكسيداتيو جزء

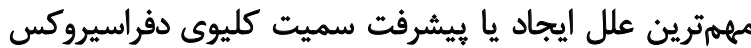

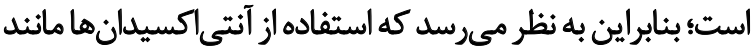

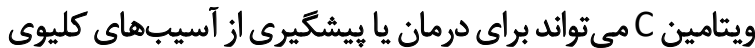

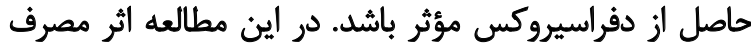
همزمان ويتامين C بر سميت كليوى دفراسيروكس بروسي دامي شد.

مواد ورشُشها
4. Deferasirox

5. Exjade 
با اسيكتروفتومتر (SpectroLab 7500 UV) ساخت انكليس

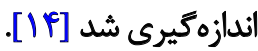

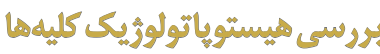

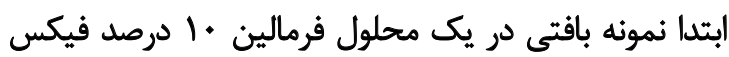

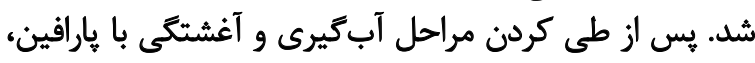

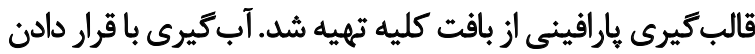

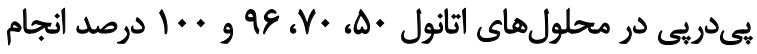

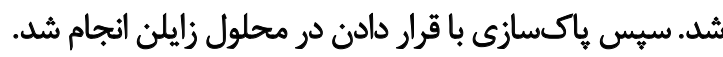

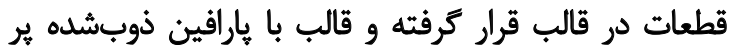

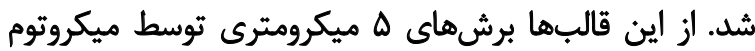

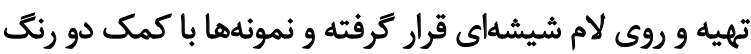

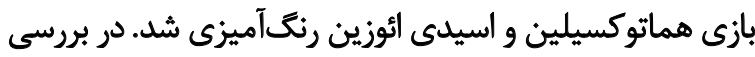

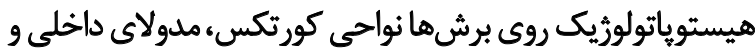

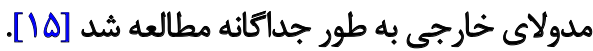

در بخش كلومرولى تغييرات فضاى كيسول بومني، تعداد

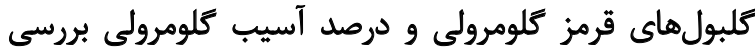

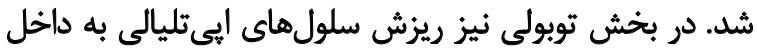

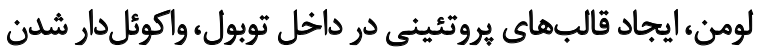

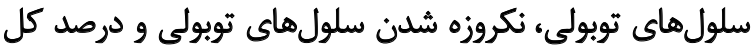

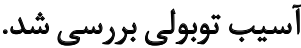

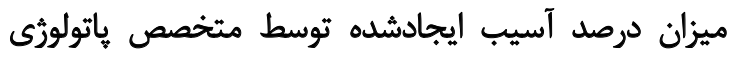

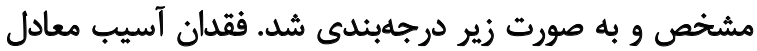

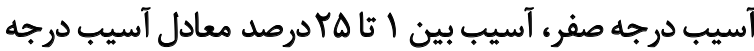

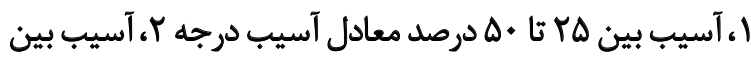

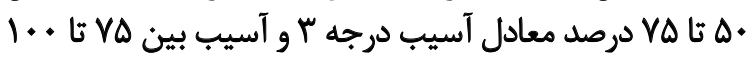

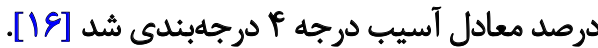

يافتهها

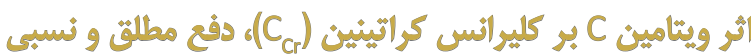

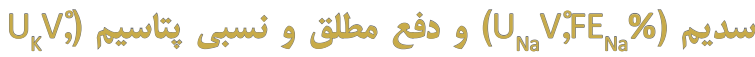

$\left(\mathrm{FE}_{\mathrm{K}} \%\right.$

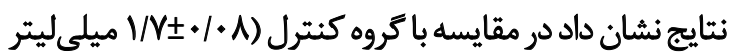

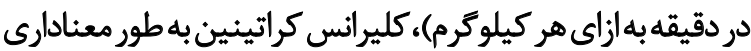

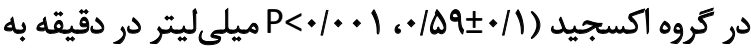

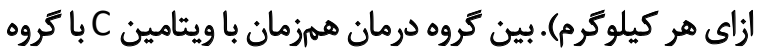

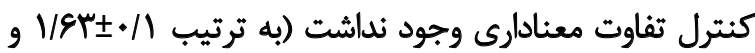

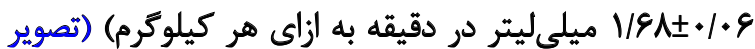

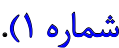

نتايج نشان داد دفع نسبى سديم به طور معنادارى در كروه

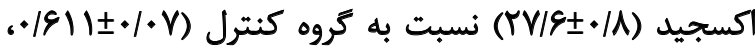

fr

UKV( $\mu \mathrm{mol} / \mathrm{min} \cdot g k w)=\left(V^{\circ} U_{k}\right) / 1000$

$\mathrm{FE}_{\mathrm{Na}}=\left(\mathrm{UNa} \times \mathrm{P}_{\mathrm{Cr}}\right) /\left(\mathrm{PNa} \times \mathrm{U}_{\mathrm{Cr}}\right) \times 100$

$\mathrm{FE}_{\mathrm{K}}=\left(\mathrm{Uk} \times \mathrm{P}_{\mathrm{Cr}}\right) /\left(\mathrm{Pk} \times \mathrm{U}_{\mathrm{Cr}}\right) \times 100$

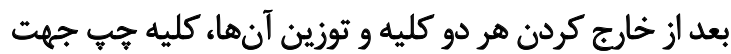

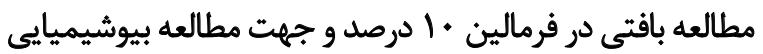

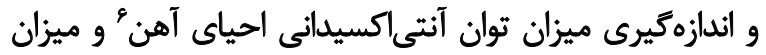

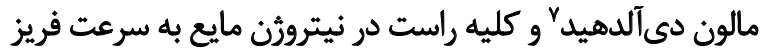

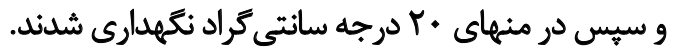

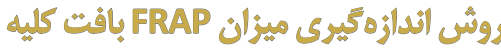

ظرفيت آنتىاكسيدانى نمونهها با استفاده از روش بنزي بنزي

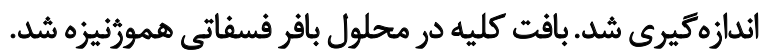

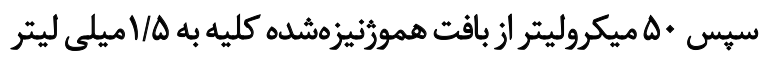

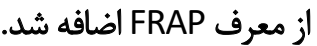

TPTZ در حضور مواد آنتىاكسيدان احياشده و باد Fe3+

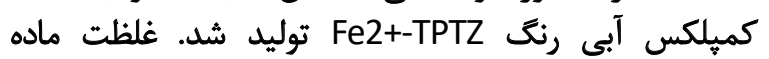

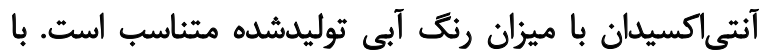
استفاده از دسثكاه اسيكتروفتومتر (SpectroLab 7500 UV)

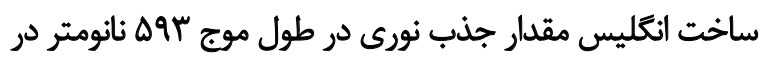

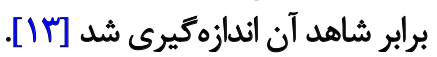

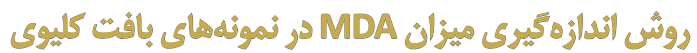

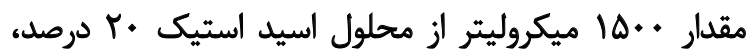

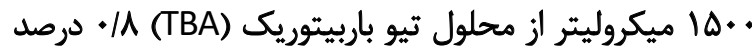

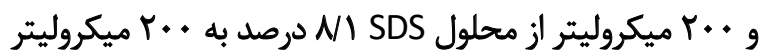

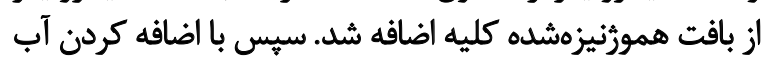

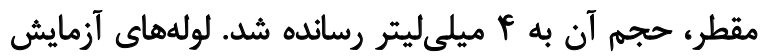

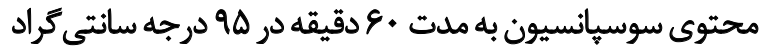

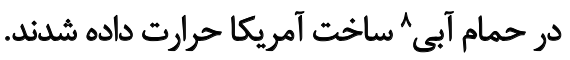

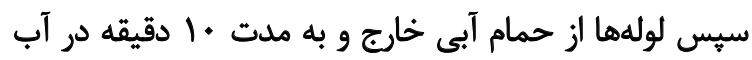

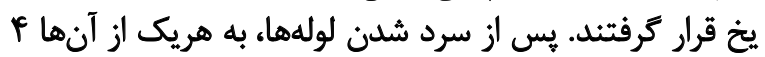

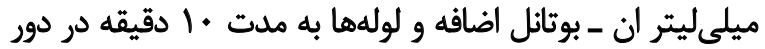

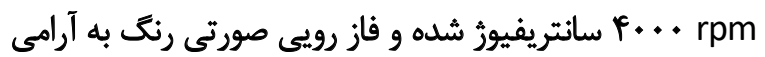

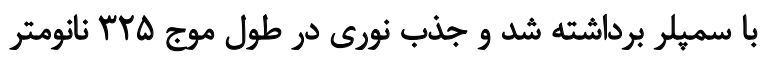

6. Ferric Reducing Antioxidant Power (FRAP)

7. Malondialdehyde (MDA)

8. DUBNOFF 


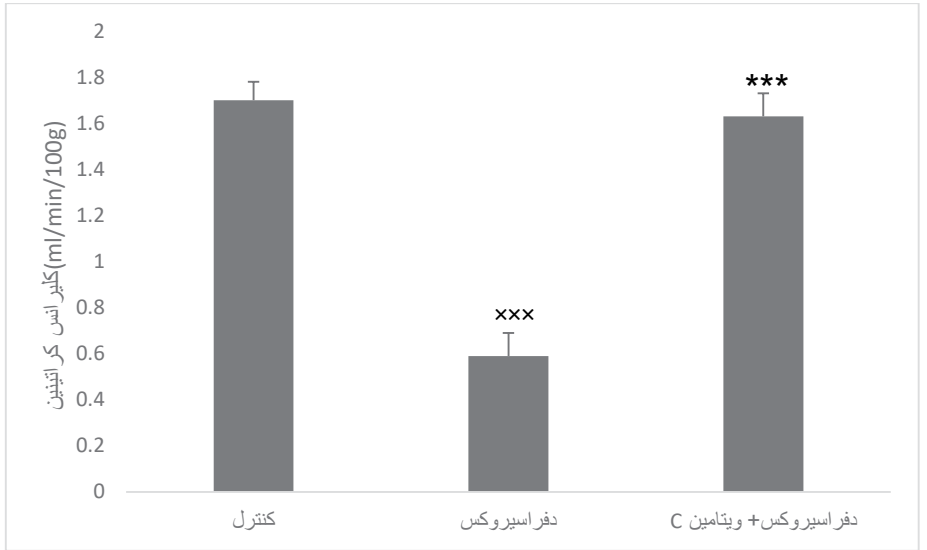

(s)

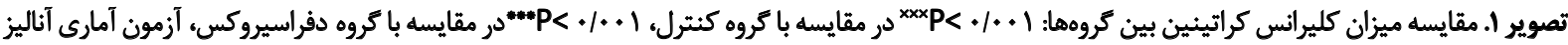

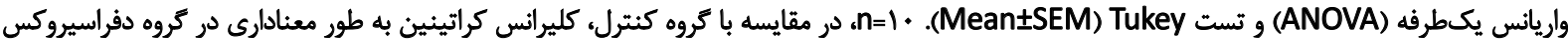

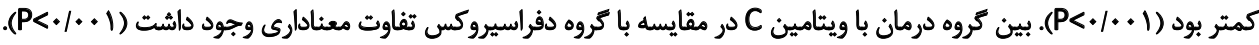

نتايج نشان داد دفع مطلق سديم در كروه دفراسيروكس

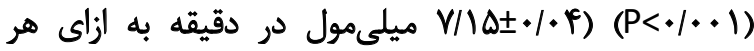

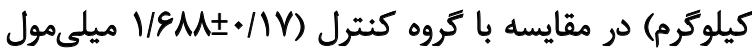

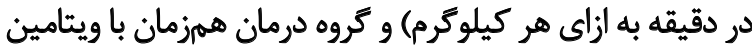

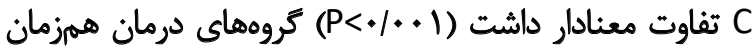

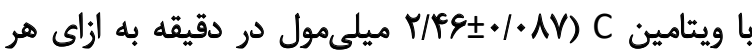
كيلوكرم) با كروه كنترل تفاوت معنادار داشت.

نتايج نشان داد دفع مطلق يتاسيم در كروه دفراسيروكس

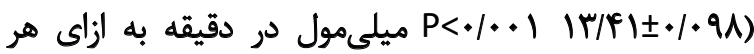

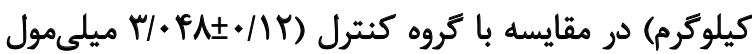

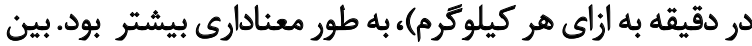

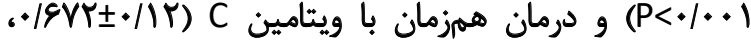

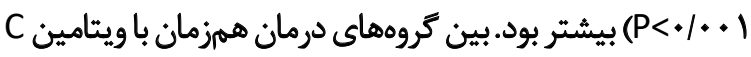

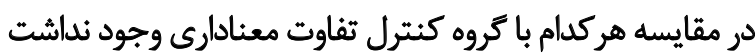

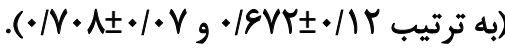

نتايج نشان داد در تروه دفراسيروكس دفع نسبى يتاسيم

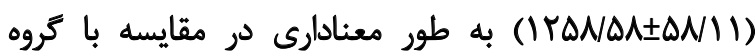

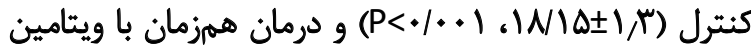

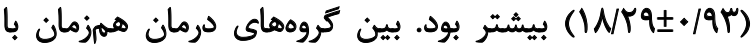

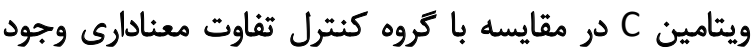

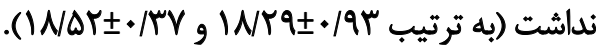

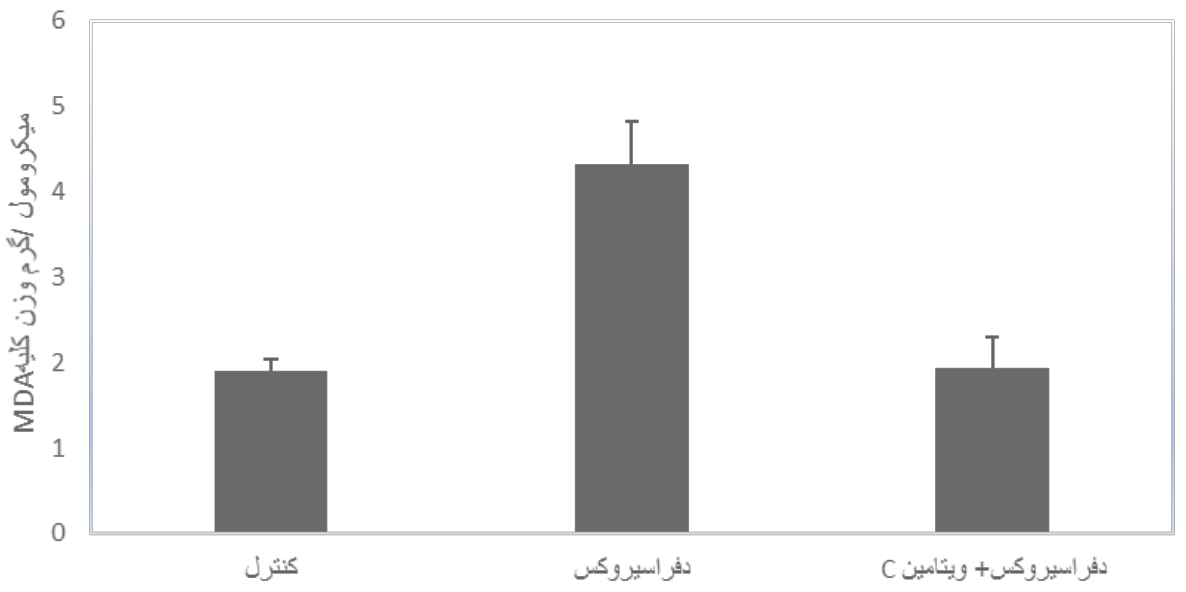

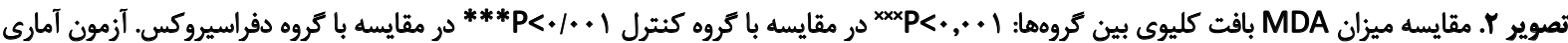

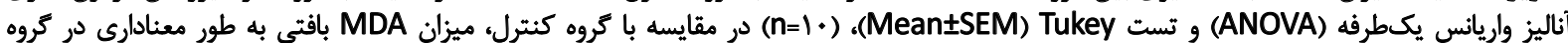

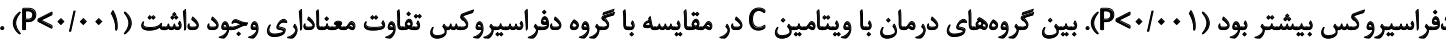




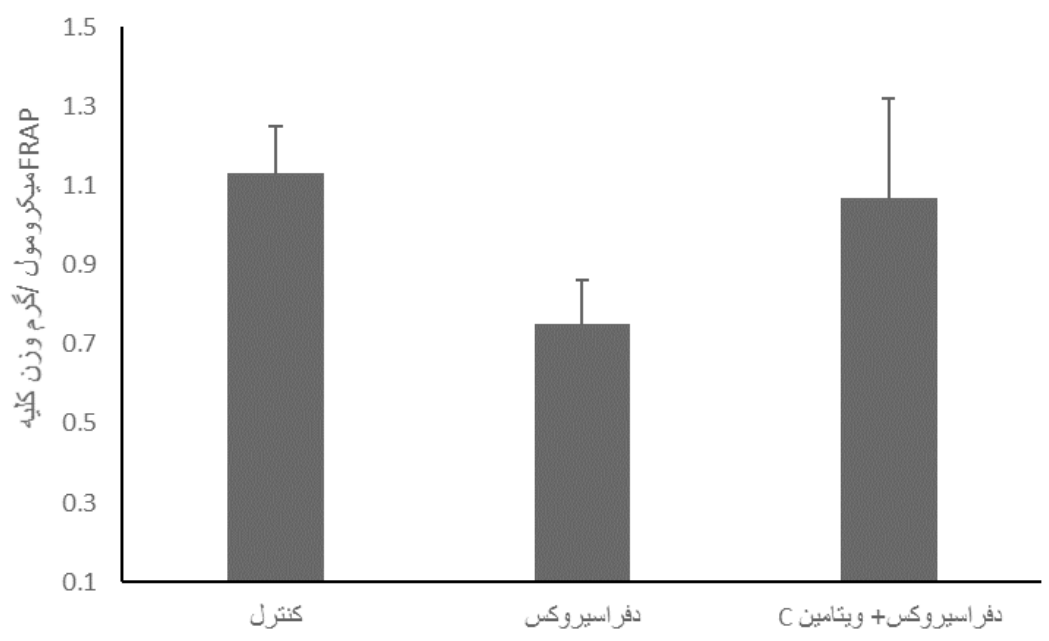

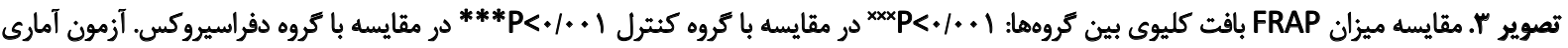

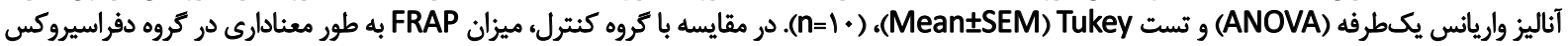

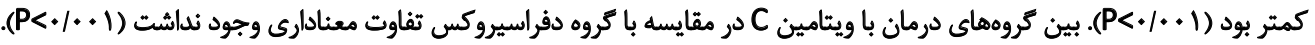

\section{معنادارى نداشت.}

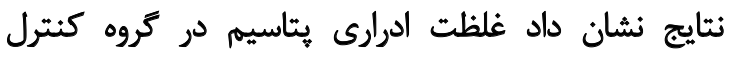
(جF/FVI+/FQ)

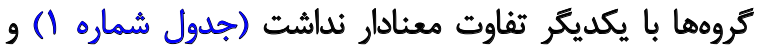

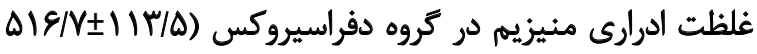

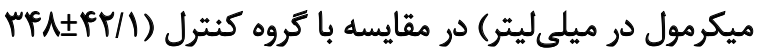

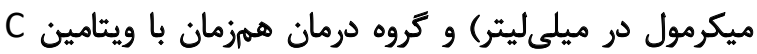

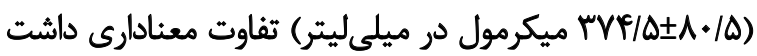

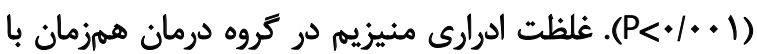

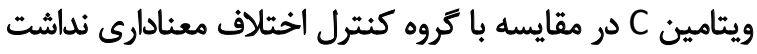

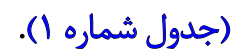

نتايج نشان داد كه اسمولاليته ادرار در كروه دفراسيروكس

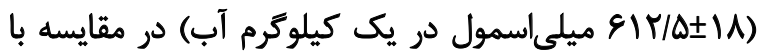

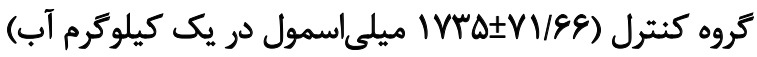

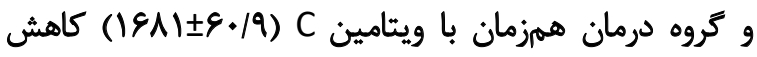

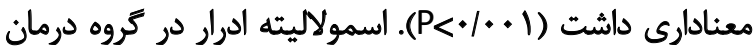

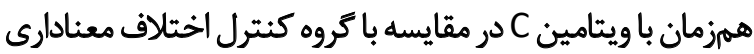

$$
\text { نداشت (جدول شماره بان (T). }
$$

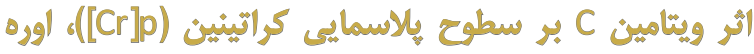

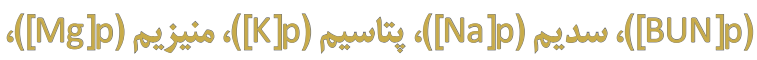

$$
\text { ([osmol]p) d d עowl }
$$

نتايج نشان داد كه غُلظت يلاسمايي كراتينين در كروه

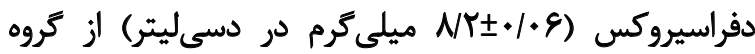

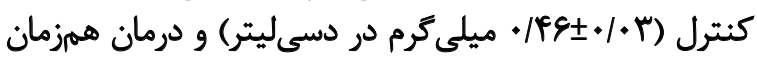

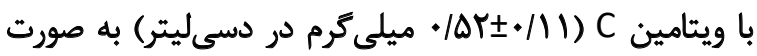

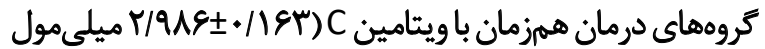

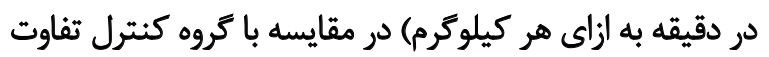
معنادارى وجود نداشت.

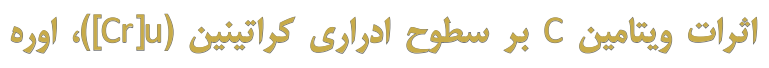

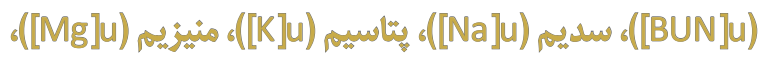

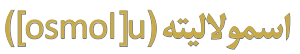

نتايج نشان داد غلظت ادرارى كراتينين در كروه دفراسيروكس

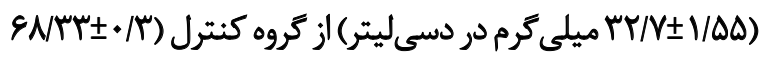

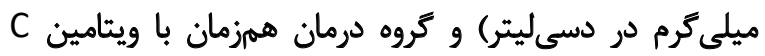

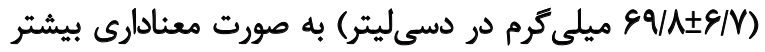

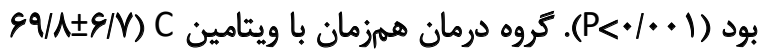

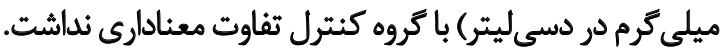
در مورد غُلظت ادرارى اوره نتثايج نشان داد درئروه كنترل

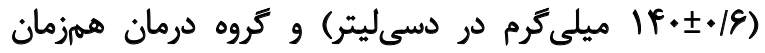

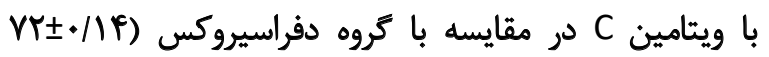

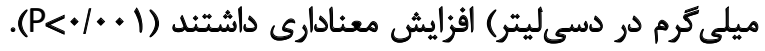

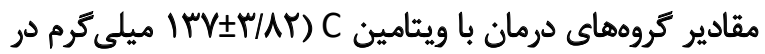

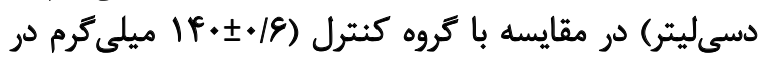

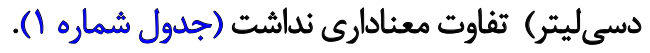
نتايج حاصله در مورد غلظت ادرارى سديم نشان داد كه گروه

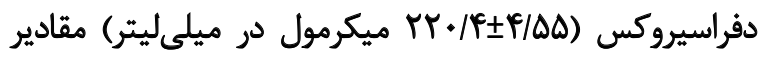

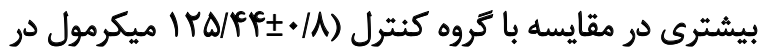

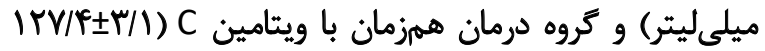

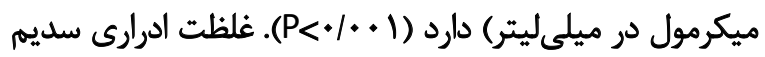

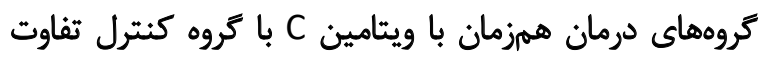


جدول ا. اثرات ويتامين C بر كليرائس كراتينين، غلظت يلاسماييى و ادرارى كراتينين، اوره،سيمهيتاسيم و منيزيم

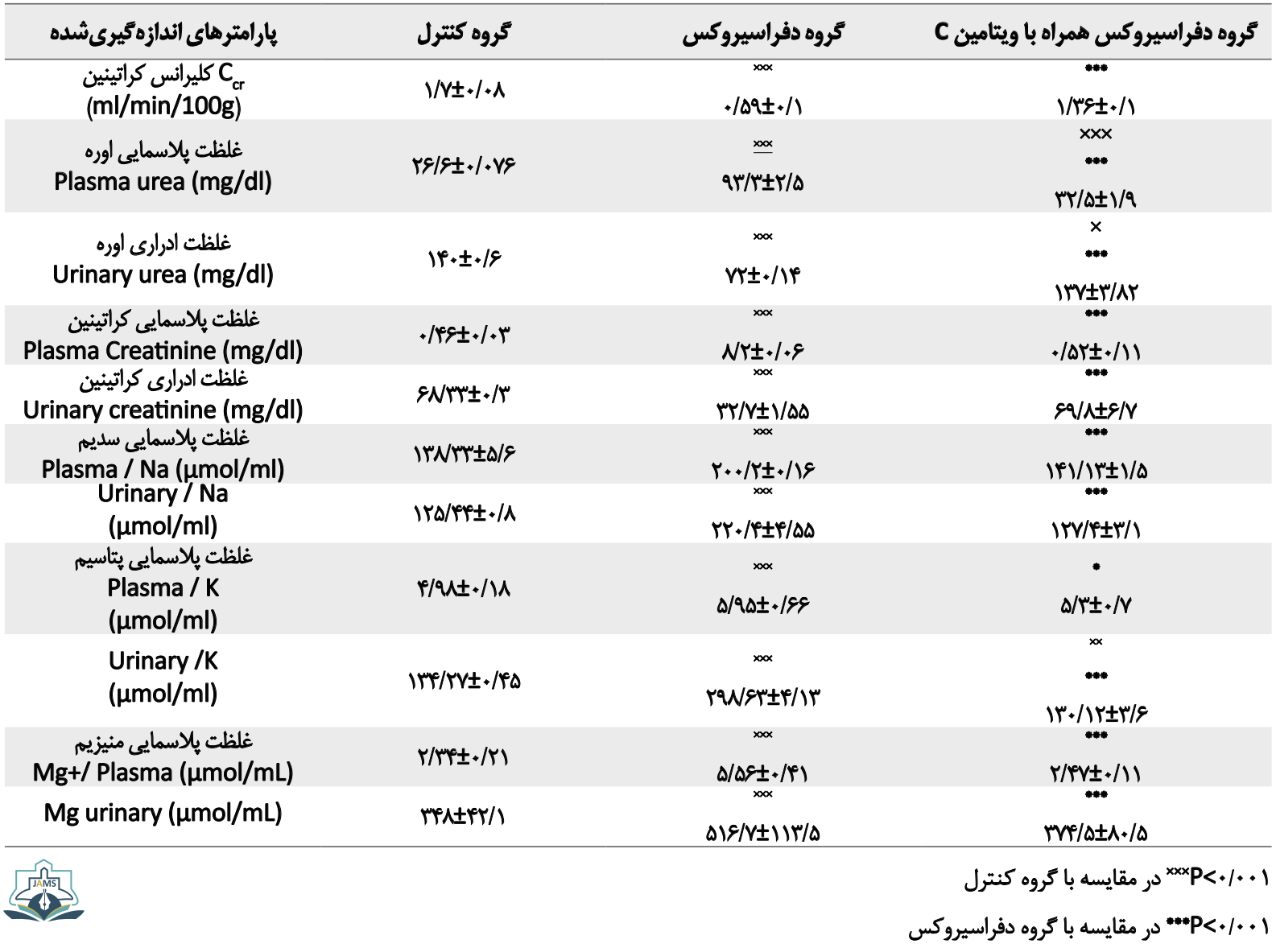

نداشت (جدول شماره ().

نتايج نشان داد كه دفراسيروكس، غلظت بِاسلاسمايى بتاسيم

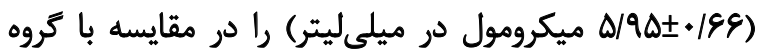

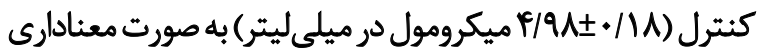

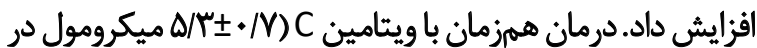

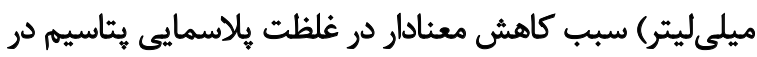

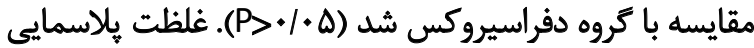

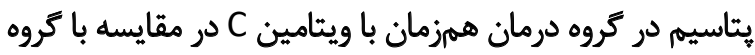

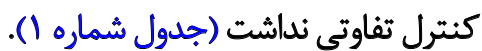

بروسى نتايج نشان داد كه در غلظت منيزيم يلاسما كَروه

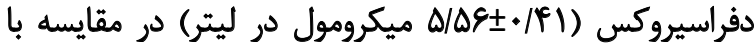

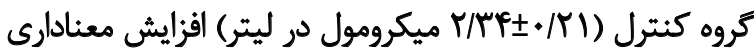

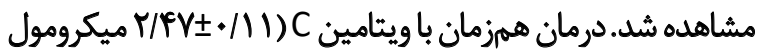

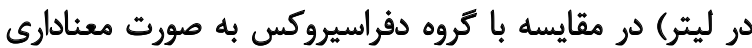

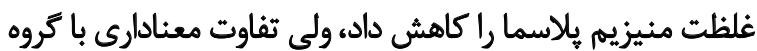
كنترل نداشت.

نتايج نشان داد كه اسمولاليته پيلاسما در كروه دفراسيروكس

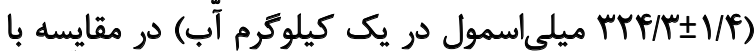

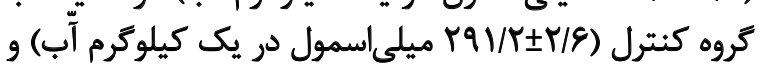

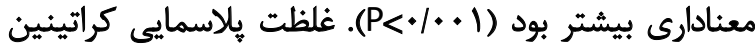

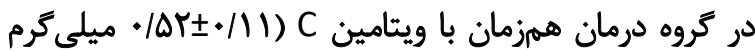

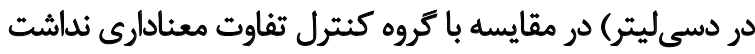

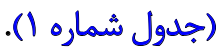

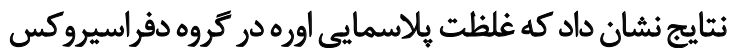

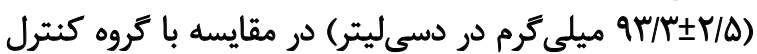

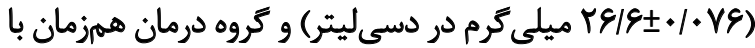

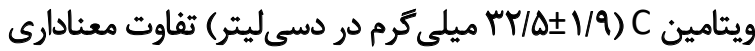

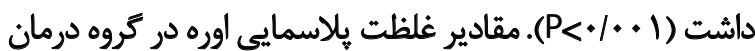

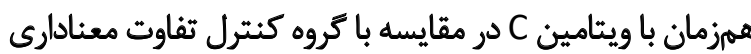
نداشت (جدول شماره ()).

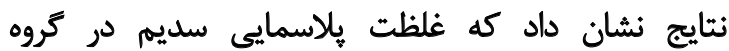

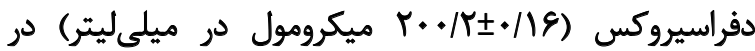

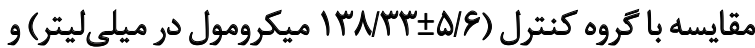

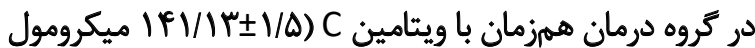

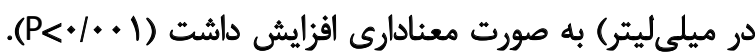

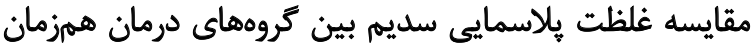

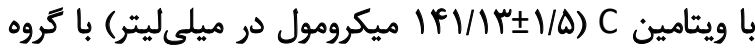

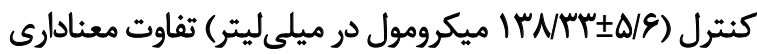


جدول r. اثرات ويتامين C بر اسمولاليته ادرار، يلاسما، دفع نسبى و مطلق سديم، يتاسيه، ميزان FRAP, MDA

\begin{tabular}{|c|c|c|c|}
\hline 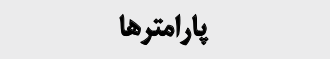 & كيروه كتترل & كروه دفراسيروكس & كروه دفراسيروكس همراه با ويتامين C \\
\hline $\begin{array}{c}\text { اسمولاليته يلاسما } \\
\text { Plasma Osmolality } \\
\text { (mOsm/kgHro) }\end{array}$ & $(91 / T \pm T / 8$ & $\underbrace{\infty}_{M}$ & $\begin{array}{c}* * * \\
r q 4 / \backslash \pm N /\end{array}$ \\
\hline $\begin{array}{c}\text { اسمولاليته ادرار } \\
\text { Urinary osmolality } \\
\text { (mOsm/kgHYO) }\end{array}$ & $|V r \Delta \pm V| / \& \varepsilon$ & $\frac{\operatorname{sox}}{\operatorname{sir} / \Delta \pm \| \Lambda}$ & $|\varepsilon \wedge| \pm 8 \cdot / 9$ \\
\hline FE Na\% & $\cdot 1811 \pm \cdot 1 \cdot v$ & $\begin{array}{c}x+x \\
M / E \pm+/ 1\end{array}$ & •/ENTE+/Ir \\
\hline UNaVo $(\mathrm{mmol} / \mathrm{min} / \mathrm{kg})$ & $V / \& M$ & $V / 1 \Delta \pm . / \%$ & $r / P \& \pm . / \cdot A V$ \\
\hline FE K\% & $|\mathcal{N} \backslash \Delta \pm| / T$ & 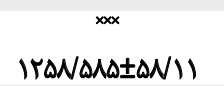 & Wrat*/ar \\
\hline $\begin{array}{c}\text { UKVo } \\
(\mathrm{mmol} / \mathrm{min} / \mathrm{kg})\end{array}$ & M/PAt./Tr & $|r / F| \pm+1.9$ & r/UEt+/IET \\
\hline MDA ( $\mu \mathrm{mol} / \mathrm{gkw})$ & 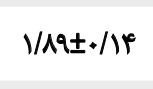 & $F / T I \pm \cdot / Q$ & $1 / q 4 \pm=/ T \Delta \Delta$ \\
\hline FRAP ( $\mu \mathrm{mol} / \mathrm{gkw})$ & MITE./K & $\begin{array}{c}x 0 x \\
.|V \Delta \pm+| 8 \mid\end{array}$ & $V+r \pm+/ 4 \Delta$ \\
\hline
\end{tabular}

نتايج اين مطالعه نشان داد كه ميزان FRAP بافت كليه در كروه

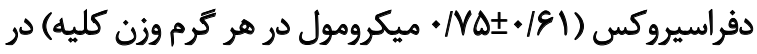

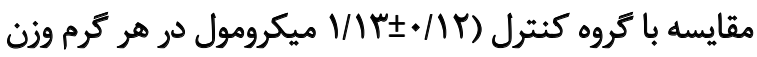

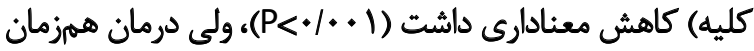

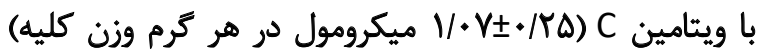

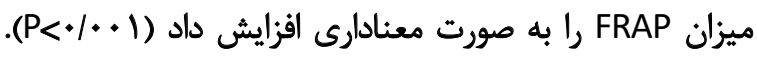

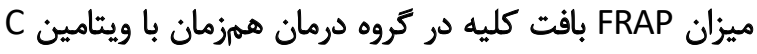

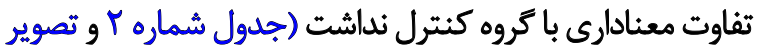

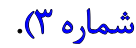

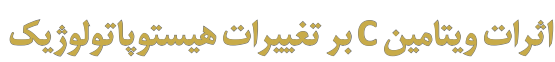

اثرات دفراسيروكس و نيز اثرات ويتامين C بر تغييرات

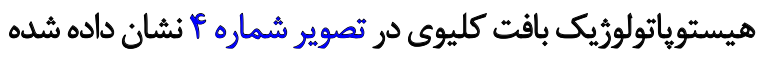

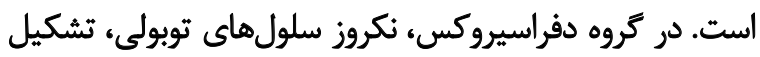

كروه درمان همزمان با ويتامين C C

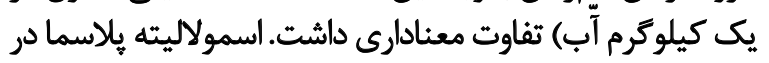

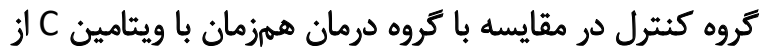

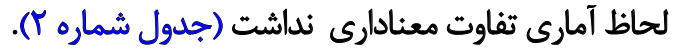

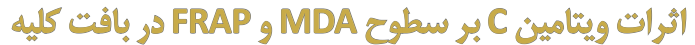

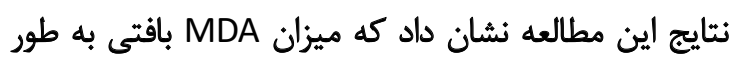
معنادارى در كروه دفراسيروكس (D) (A)

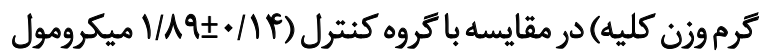

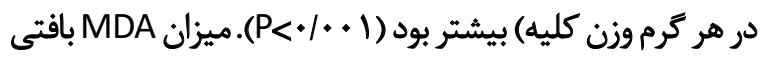

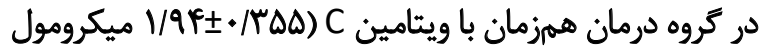

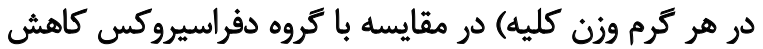

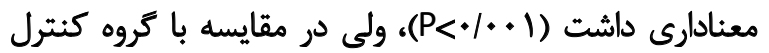
تفاوت معنادارى نداشت (جدول شماره Y و تصوير شماره Y).

جدول r. درجهبندى بافتششئاختى نموئهها

\begin{tabular}{|c|c|c|c|c|c|}
\hline $\begin{array}{l}\text { Parameters } \\
\text { Groups }\end{array}$ & Necrosis & $\begin{array}{c}\text { Protein } \\
\text { formations }\end{array}$ & $\begin{array}{c}\text { Tubular cell } \\
\text { Vacuolization }\end{array}$ & Bowman's space & $\begin{array}{l}\text { Decreased RBC in } \\
\text { Bowman's space }\end{array}$ \\
\hline Control & . & + & . & - & - \\
\hline Exjade(Ex) & xoxp & xom & $x \times p$ & $x x_{p}$ & Ixy \\
\hline Ex+Vitamin C(VC) & $\cdots$ & $\cdots$ & $\cdots$ & $\cdots$ & $\cdots$ \\
\hline
\end{tabular}




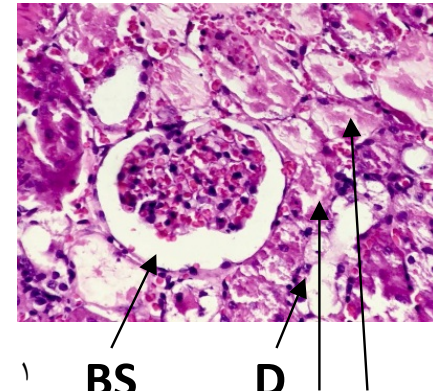

BS

v

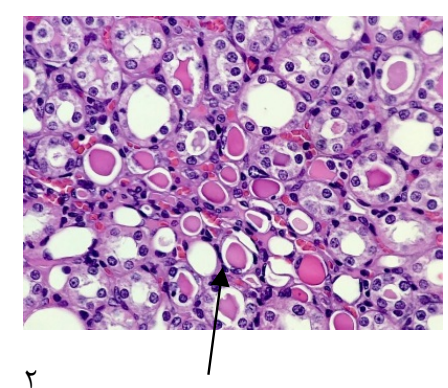

C

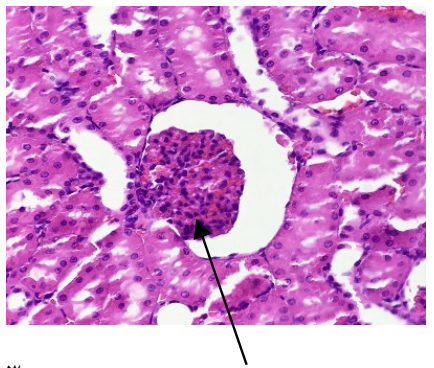

RBC
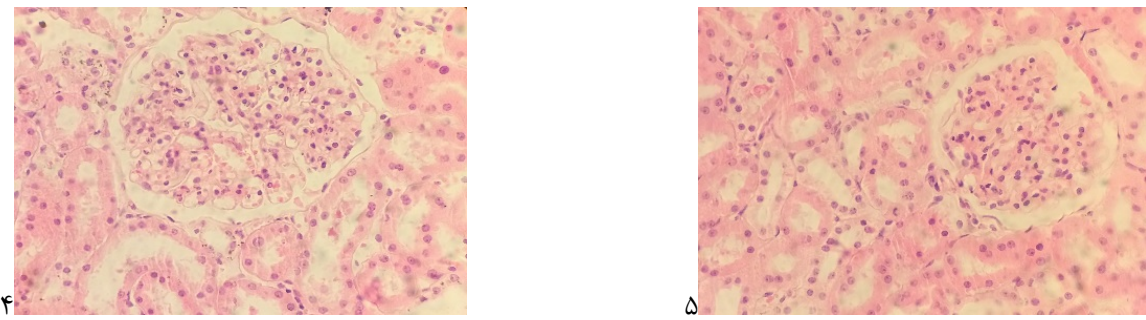

$\mathrm{RBC}=$ red blood cells, $\mathrm{BS}=$ Bowman's space, $\mathrm{C}=$ intratubular cast, $\mathrm{D}=$ downfall, $\mathrm{V}=$ vacuolization, $\mathrm{N}=$ necrosis

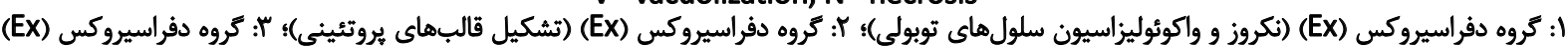

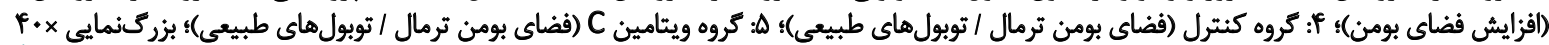
(sing

تصوير f. تصاوير نمونههاي بافت كليوى

نتايج اين تحقيق نشان داد كه درمان همزمان اندان با ويتامين

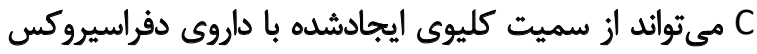

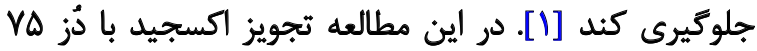

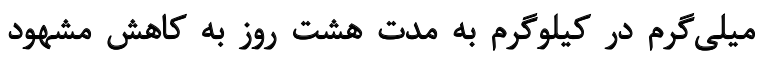

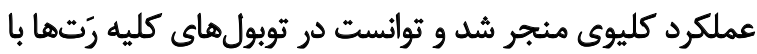

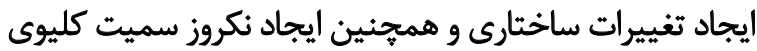

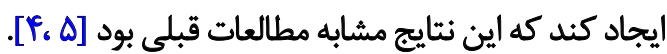

باردر اين مطالعه سميت كليوى دفراسيروكس با سنجش

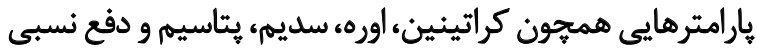

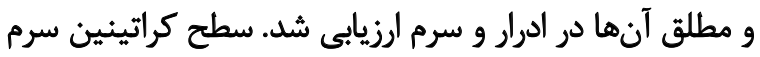

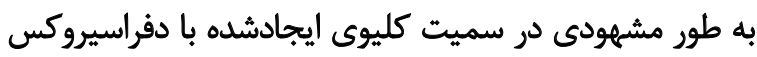

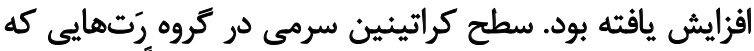

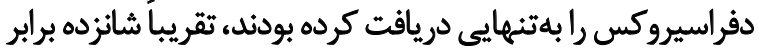

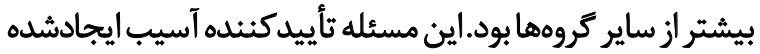
با دفراسيروكس و سميت كليوى آن است.

يكى از عوامل مؤثر در ايجاد آسيب كليوى ايجادشده با

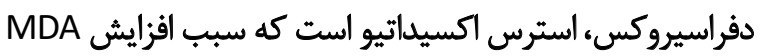

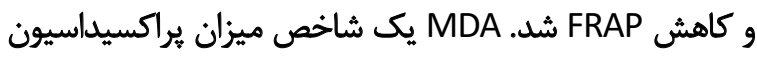

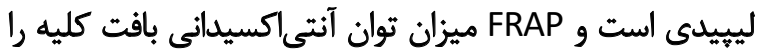

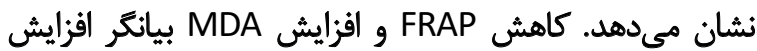

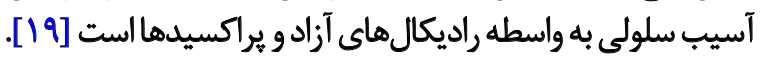
در اين مطالعه تمام رَتهاى درمانشده با ويتامين C نسبت
قالبهاى بروتئينى در لومن توبول، واكوئوليزاسيون سلولهاى

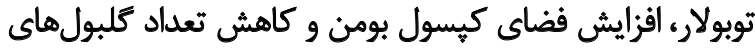

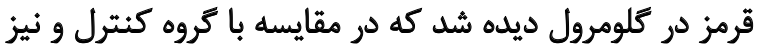

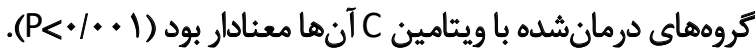

بررسى هيستوياتولوزيك نمونههاى كليوى حاصل از تروه

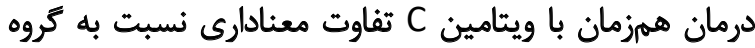

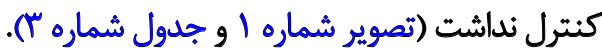

بٕ:

نتايج اين مطالعه نشان داد كه ويتامين C با كاهش اوره،

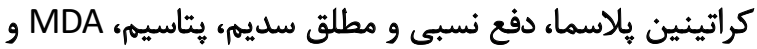

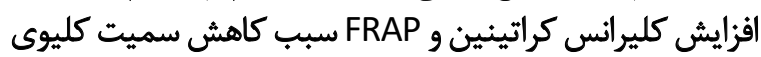

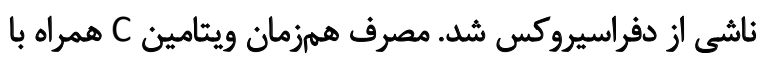
دفراسيروكس با كاهش استرس اكسيداتيو سبب حفاظت وفين كليهها

شد.

مطالعات قبلى نشان داد كه ويتامين C ميزان استرس اكسيداتيو

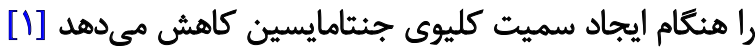

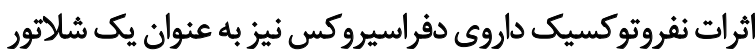

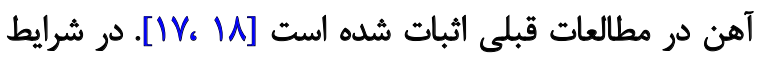

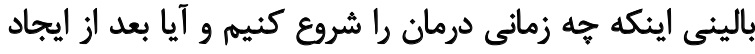

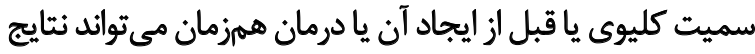

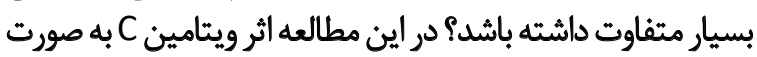

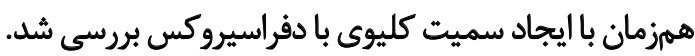


دفراسيروكس مىتواند به علت هربيد احوست بودن به به راحتى

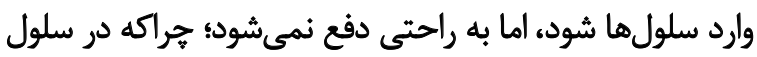

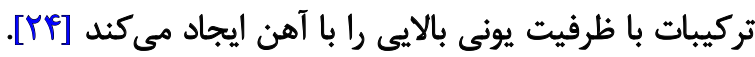

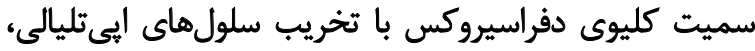

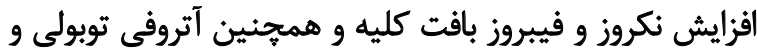

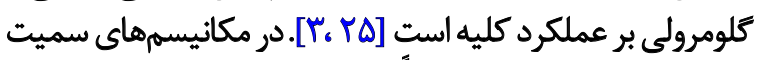

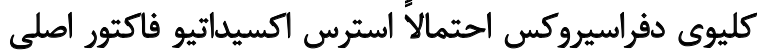

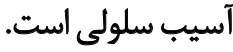

اعثقاد بر اين است كه سميت كليوى دفراسيروكس به علت آلت

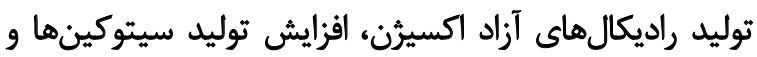

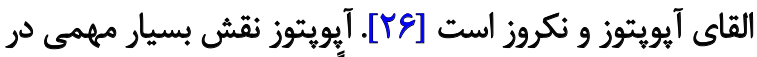

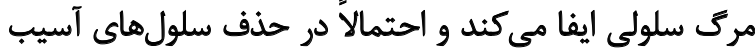

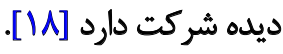

بسيارى از داروهايى كه به طور عمومى و شايع تجويز مى شيوند، از جمله آمفوتريسين ب، سيكلوسيورين، مهاركنيندهائهاي

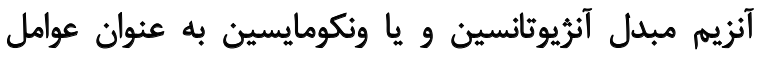

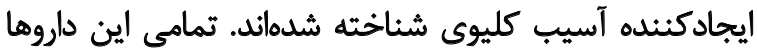

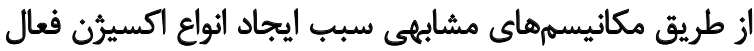

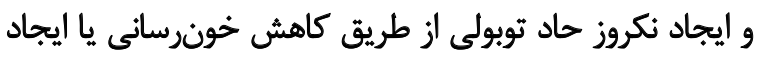

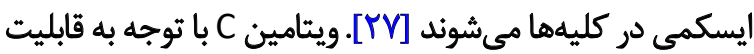

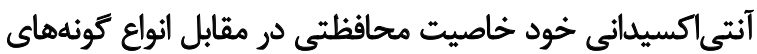

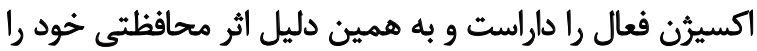

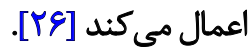

تجويز ويتامين C باعث حفظ معنادار كليرانس كراثينين

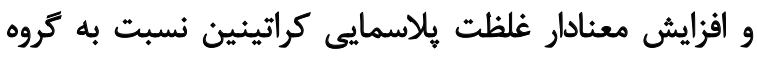

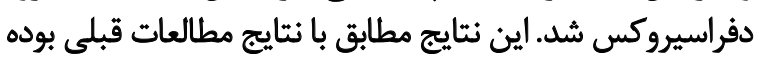

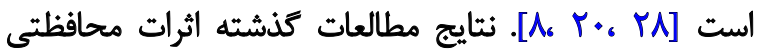

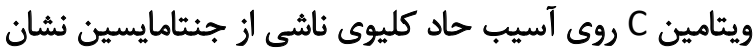

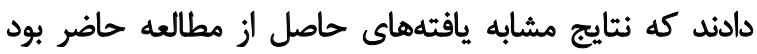

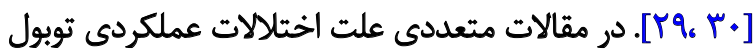

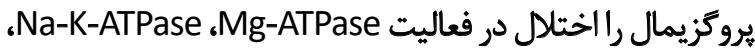

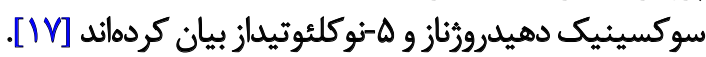

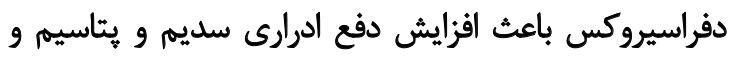
FEN و FENa

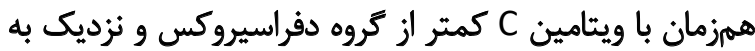

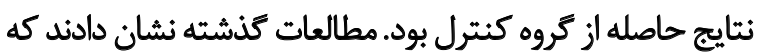

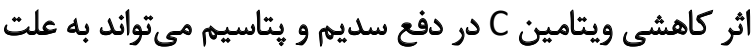
حفظ عملكرد جذبى توبولى سديم و يتاسيم باشد.

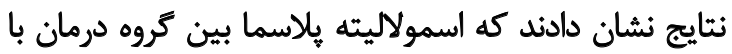

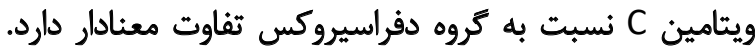

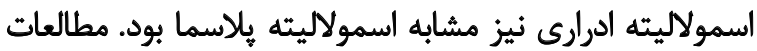

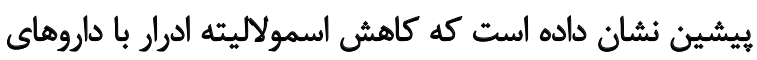

به كروه دفراسيروكس سطوح بايينترى از MDA را داشتند.

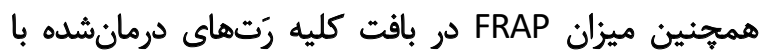

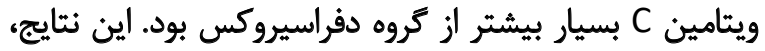

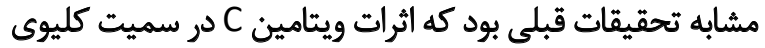
ناشى از داروهاى مختلف را بررسى كرده بودند [A] استونداك و همكارانش نشان دادند كه تجويز كليسرول، ميزان

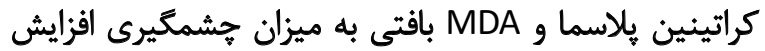

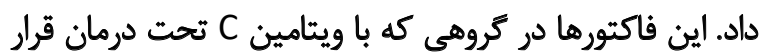

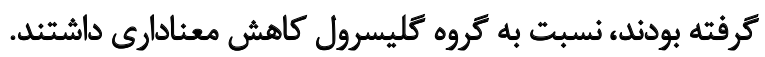

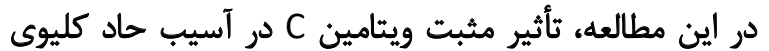

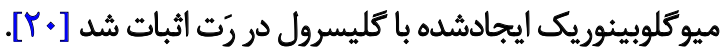

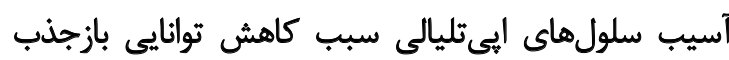

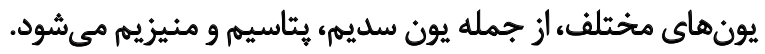

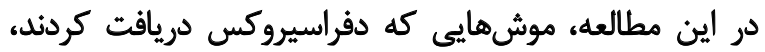

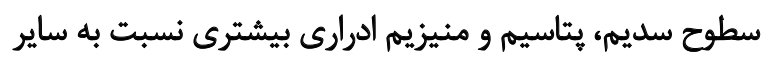

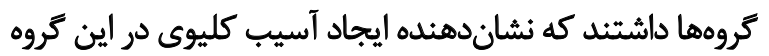

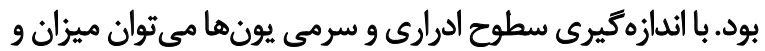

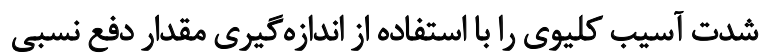
و مطلق اين يونها مشخص كرد.

دفع نسبى سديم و يتاسيم حاصل ميزان بازجذب و ترشح

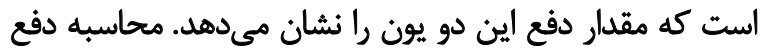

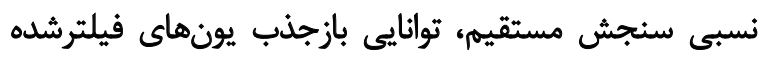

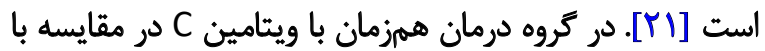

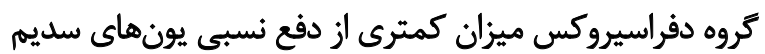

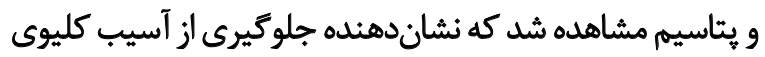

بوض.

موريرا و همكارانش نشان دادند كه ويتامين C با كاهش كانش

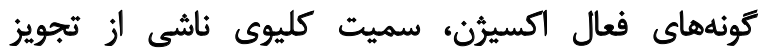

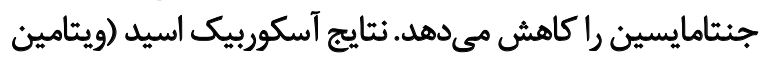

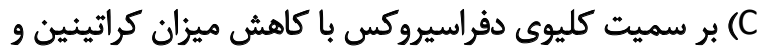
اوره خون، ميزان MDA بافتى با كاهش استرس اكئري اكسيداتيو مشابيه

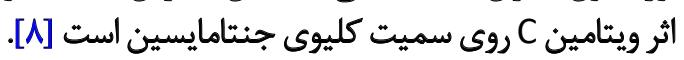

نتايج اين مطالعه نشان داد كه داروى دفراسيروكس مي تواند إندي

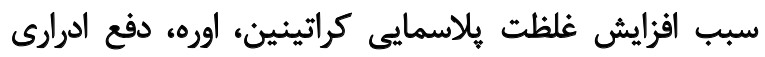

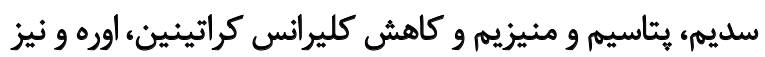

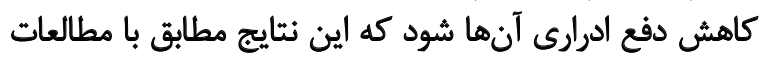

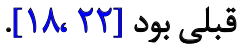
افزايش راديكال هاي آزاد سبب ايجاد اختلال و آسيب كليوى

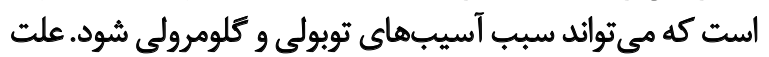

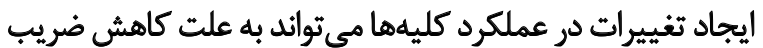

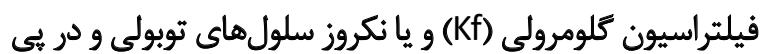

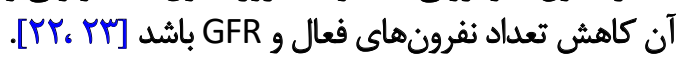




$$
\text { the cor }
$$

نتايج اين تحقيق حاصل يايان نامه آقاى طه فريدونى دانشجوى

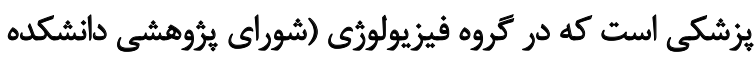

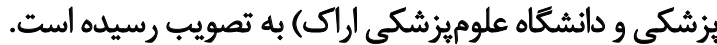

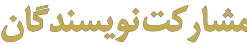

مفهومسازى: هارسا يوسفى جايجان؛ روش شيناسى، اعتبارسنجى

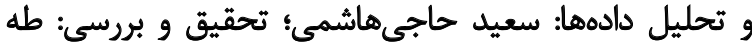

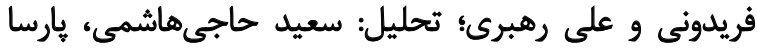

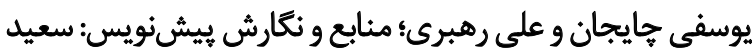
حاجى هاشمى و طه فريدونى

$$
\text { تعاروض منأقع }
$$

بنابر اظهار نويسندكان اين مقاله تعارض منافع ندارد.

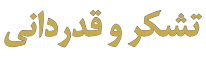

تويسندكان از معاونت محترم آموزش و معاونت محترم

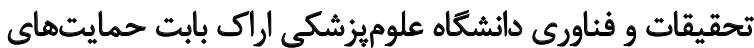
مالى از اين تحقيق كمال تشكر را دارند.
AQP2 بفروكسيك مىتواند به علت اثر آن روى كاهش بيان

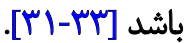

درمان با دفراسيروكس و آسيبهاى توبولى در مدلهاى

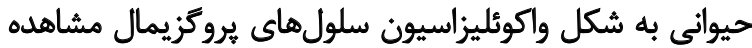

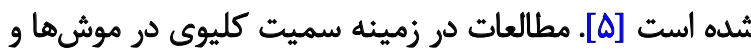

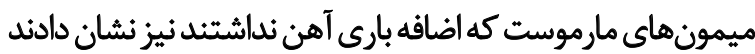

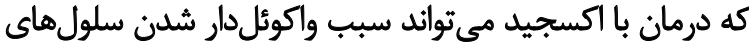

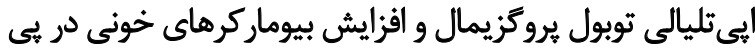

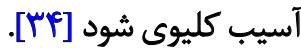

در مدل آزمايشى ما، ارزيابىهاى بافتشناسى و واتولوزئيك

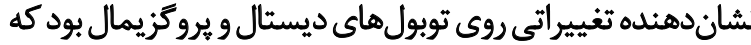

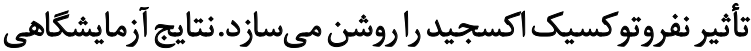

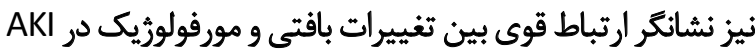

$$
\text { ناشى از اكسجيد بود. }
$$

مطالعات بافتشناسى نشان دادند كه اكسجيد باعث افزٔزيش

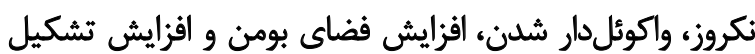

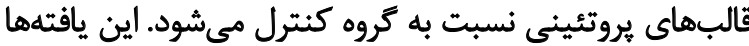
مشابه كزارشات مطالعه كارسيا دياز بود [11] ] هدف ما بررسى درمان همزمان سميت كليوى بود؛ جراكه در

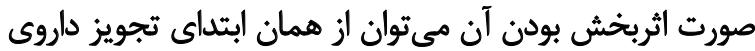

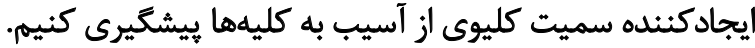

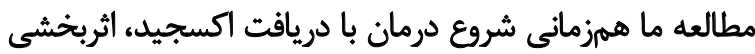

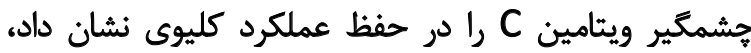

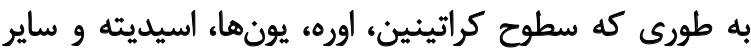

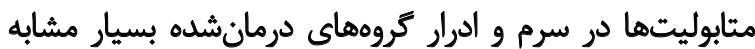

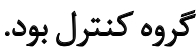

$$
\text { نتيجه نميرى }
$$

استفاده از ويتامين C به صورت درمان همزمان با جلوكيرى از

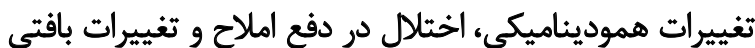

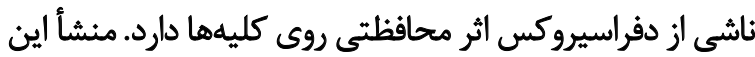

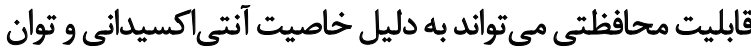
به دام انداختن راديكال هاي آزاد باشيد.

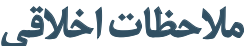

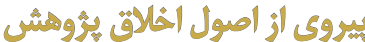

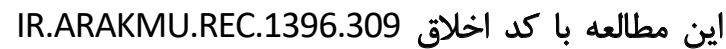
در كميثه اخلاق در يروهش دانشكاه علوميزشكى ارئ اراك به ثبت

$$
\text { رسيده است. }
$$




\section{References}

[1] Hirschberg R, Bennett W, Scheinman J, Coppo R, Ponticelli C. Acute kidney injury due to deferoxamine in a renal transplant patient. Nephrol Dial Transplant. 2008; 23(8):2704-5. [DOI:10.1093/ndt/gfn278] [PMID]

[2] Al-Khabori M, Bhandari S, Al-Huneini M, Al-Farsi K, Panjwani V, Daar S. Side effects of deferasirox iron chelation in patients with beta thalassemia major or intermedia. Oman Med J. 2013; 28(2):121-4. [DOI:10.5001/ omj.2013.31] [PMID] [PMCID]

[3] Dubourg L, Laurain C, Ranchin B, Pondarré C, Hadj-Aïssa A, SigaudoRoussel D, et al. Deferasirox-induced renal impairment in children: An increasing concern for pediatricians. Pediatr Nephrol. 2012; 27(11):211522. [DOI:10.1007/s00467-012-2170-4] [PMID]

[4] Brosnahan G, Gokden N, Swaminathan S. Acute interstitial nephritis due to deferasirox: A case report. Nephrol Dial Transplant. 2008; 23(10):3356-8. [DOI:10.1093/ndt/gfn423] [PMID]

[5] Martin-Sanchez D, Gallegos-Villalobos A, Fontecha-Barriuso M, Carrasco S, Sanchez-Niño MD, Lopez-Hernandez FJ, et al. Deferasirox-induced iron depletion promotes BclxL downregulation and death of proximal tubular cells. Sci Rep. 2017; 7:41510. [DOI:10.1038/srep41510] [PMID] [PMCID]

[6] Kadkhodaee M, Khastar H, Arab HA, Ghaznavi R, Zahmatkesh M, Mahdavi-Mazdeh M. Antioxidant vitamins preserve superoxide dismutase activities in gentamicin-induced nephrotoxicity. Transplant Proc. 2007: 39(4):864-5. [DOI:10.1016/j.transproceed.2007.02.038] [PMID]

[7] Zhong X, Zeng M, Bian H, Zhong C, Xiao F. An evaluation of the protective role of vitamin $C$ in reactive oxygen species-induced hepatotoxicity due to hexavalent chromium in vitro and in vivo. J Occup Med Toxicol. 2017; 12:15. [DOI:10.1186/s12995-017-0161-x] [PMID] [PMCID]

[8] Moreira MA, Nascimento MA, Bozzo TA, Cintra A, da Silva SM, Dalboni $M A$, et al. Ascorbic acid reduces gentamicin-induced nephrotoxicity in rats through the control of reactive oxygen species. Clin Nutr. 2014; 33(2):296-301. [DOI:10.1016/j.clnu.2013.05.005] [PMID]

[9] Chen X, Touyz RM, Park JB, Schiffrin EL. Antioxidant effects of vitamins C and $E$ are associated with altered activation of vascular NADPH oxidase and superoxide dismutase in stroke-prone SHR. Hypertension. 2001; 38(3 Pt 2):606-11. [DOI:10.1161/hy09t1.094005] [PMID]

[10] Brewer C, Otto-Duessel M, Lykkesfeldt J, Nick H, Wood JC. Ascorbate status modulates reticuloendothelial iron stores and response to deferasirox iron chelation in ascorbate-deficient rats. Exp Hematol. 2012 40(10):820-7. [DOI:10.1016/j.exphem.2012.06.005] [PMID]

[11] Ghaznavi R, Kadkhodaee M, Khastar H, Zahmatkesh M. [Renal oxidative stress status and histology in gentamicin nephrotoxicity: The effects of antioxidant vitamins (Persian)]. Tehran Univ Med J. 2006; 64(5):15-22. http://tumj.tums.ac.ir/article-1-944-en.html

[12] Ahmadi F, Hajihashemi S, Rahbari A, Ghanbari F. Effects of nitroglycerine on renal ischemia-reperfusion injury in adult male rats. Drug Res (Stuttg). 2019; 69(11):612-20. [DOI:10.1055/a-0958-1987] [PMID]

[13] Benzie IF, Strain JJ. The ferric reducing ability of plasma (FRAP) as a measure of "antioxidant power": The FRAP assay. Anal Biochem. 1996; 239(1):70-6. [DOI:10.1006/abio.1996.0292] [PMID]

[14] Ohkawa H, Ohishi N, Yagi K. Assay for lipid peroxides in animal tissues by thiobarbituric acid reaction. Anal biochem. 1979; 95(2):351-8. [DOI:10.1016/0003-2697(79)90738-3]

[15] Aydin G, Gökçimen A, Öncü M, Çicek E, Karahan N, Gökalp O. Histopathologic changes in liver and renal tissues induced by different doses of diclofenac sodium in rats. Turk J Vet Anim Sci. 2003;
27(5):1131-40. https://www.researchgate.net/publication/281888383

[16] Hajihashemi S, Jafarian T, Ahmadi M, Rahbari A, Ghanbari F. Ameliorative effects of zataria multiflora hydro-alcoholic extract on Gentamicin induced Nephrotoxicity in rats . Drug Res (Stuttg). 2018; 68(7):387-94. [DOI:10.1055/s-0043-124968] [PMID]

[17] Westenfelder C, Arevalo GJ, Crawford PW, Zerwer P, Baranowski RL, Birch FM, et al. Renal tubular function in glycerol-induced acute renal failure. Kidney Int. 1980; 18(4):432-44. [DOI:10.1038/ki.1980.156] [PMID]

[18] Díaz-García JD, Gallegos-Villalobos A, Gonzalez-Espinoza L, SanchezNiño MD, Villarrubia J, Ortiz A. Deferasirox nephrotoxicity-the knowns and unknowns. Nat Rev Nephrol. 2014; 10(10):574-86. [DOI:10.1038/ nrneph.2014.121] [PMID]

[19] Tataranni T, Agriesti F, Mazzoccoli C, Ruggieri V, Scrima R, Laurenzana I, et al. The iron chelator deferasirox affects redox signalling in haematopoietic stem/progenitor cells. Br J Haematol. 2015; 170(2):236-46. [DOI:10.1111/bjh.13381] [PMID]

[20] Ustundag S, Yalcin O, Sen S, Cukur Z, Ciftci S, Demirkan B. Experimental myoglobinuric acute renal failure: The effect of vitamin C. Ren Fail. 2008; 30(7):727-35. [DOI:10.1080/08860220802212965] [PMID]

[21] Steiner RW. Interpreting the fractional excretion of sodium. Am J Med. 1984; 77(4):699-702. [DOI:10.1016/0002-9343(84)90368-1]

[22] Martínez-Salgado C, Rodríguez-Barbero A, Tavares $\mathrm{P}$, Eleno $\mathrm{N}$, López-Novoa JM. Role of calcium in gentamicin-induced mesangial cell activation. Cell Physiol Biochem. 2000; 10(1-2):65-72. [DOI:10.1159/000016335] [PMID]

[23] Savin V, Karniski L, Cuppage F, Hodges G, Chonko A. Effect of gentamicin on isolated glomeruli and proximal tubules of the rabbit. Lab Invest. 1985; 52(1):93-102. [PMID]

[24] Hider RC. Charge states of deferasirox-ferric iron complexes. Am J Kidney Dis. 2010; 55(3):614-5. [DOI:10.1053/j.ajkd.2009.10.065] [PMID]

[25] Rafat C, Fakhouri F, Ribeil JA, Delarue R, Le Quintrec M. Fanconi syndrome due to deferasirox. Am J Kidney Dis. 2009; 54(5):931-4. [DOI:10.1053/j.ajkd.2009.03.013] [PMID]

[26] Stojiljkovic N, Stoiljkovic M, Randjelovic P, Veljkovic S, Mihailovic D. Cytoprotective effect of vitamin C against gentamicin-induced acute kidney injury in rats. Exp Toxicol Pathol. 2012; 64(1-2):69-74. [DOI:10.1016/j. etp.2010.06.008] [PMID]

[27] Patel Manali B, Deshpande S, Shah G. Evaluation of efficacy of vitamin $\mathrm{E}$ and $\mathrm{N}$-acetyl cysteine in gentamicin-induced nephrotoxicity in rats. Ren Fail. 2011; 33(3):341-7. [DOI:10.3109/0886022X.2011.560987] [PMID]

[28] Miloradovic Z, Mihailovic-Stanojevic N, Grujic-Milanovic J, Ivanov M, Kuburovic G, Markovic-Lipkovski J, et al. Comparative effects of L-arginine and vitamin C pretreatment in SHR with induced postischemic acute renal failure. Gen. Physiol. Biophys. 2009; 28:105-11. http://www.physiology.org.rs/eng/htm/konf2008/gen_phys_spec. pdf\#page $=105$

[29] Saleem U, Ahmad B, Rehman K, Mahmood S, Alam M, Erum A Nephro-protective effect of vitamin $C$ and Nigella sativa oil on gentamicin associated nephrotoxicity in rabbits. Pak J Pharm Sci. 2012; 25(4):727-30. [PMID]

[30] Appenroth D, Fröb S, Kersten L, Splinter FK, Winnefeld K. Protective effects of vitamin $E$ and $C$ on cisplatin nephrotoxicity in developing rats. 
Arch Toxicol. 1997; 71(11):677-83. [DOI:10.1007/s002040050444] [PMID]

[31] Kim SW, Jeon YS, Lee JU, Kang DG, Kook H, Ahn KY, et al. Diminished adenylate cyclase activity and aquaporin 2 expression in acute renal failure rats. Kidney Int. 2000; 57(4):1643-50. [DOI:10.1046/j.15231755.2000.00008.x] [PMID]

[32] Lee J, Yoo KS, Kang DG, Kim SW, Choi KC. Gentamicin decreases the abundance of aquaporin water channels in rat kidney. Jpn J Pharmacol. 2001; 85(4):391-8. [DOI:10.1254/jjp.85.391] [PMID]

[33] Sohn EJ, Kang DG, Lee HS. Protective effects of glycyrrhizin on gentamicin-induced acute renal failure in rats. Pharmacol Toxicol. 2003; 93(3):116-22. [DOI:10.1034/j.1600-0773.2003.930302.x] [PMID]

[34] Grangé S, Bertrand DM, Guerrot D, Eas F, Godin M. Acute renal failure and Fanconi syndrome due to deferasirox. Nephrol Dial Transplant. 2010; 25(7):2376-8. [DOI:10.1093/ndt/gfq224] [PMID] 
This Page Intentionally Left Blank 